\title{
Annual and semiannual variations in the ionospheric F2-layer. I. Modelling
}

\author{
L. Zou ${ }^{1}$, H. Rishbeth ${ }^{1}$, I. C. F. Müller-Wodarg ${ }^{1,2}$, A. D. Aylward ${ }^{2}$, G. H. Millward ${ }^{2,3,4}$, \\ T. J. Fuller-Rowell ${ }^{3}$, D. W. Idenden ${ }^{4}$, R. J. Moffett ${ }^{4}$ \\ ${ }^{1}$ Department of Physics and Astronomy, University of Southampton, Southampton SO17 1BJ, UK \\ 2 Atmospheric Physics Laboratory, University College London, 67-73 Riding House Street, London WIP 7PP, UK \\ ${ }^{3}$ CIRES, University of Colorado and NOAA Space Environment Center, 325 Broadway, Boulder, CO 80303, USA \\ ${ }^{4}$ School of Mathematics and Statistics, University of Sheffield, Sheffield S3 7RH, UK
}

Received: 21 April 1999 / Revised: 29 November 1999 / Accepted: 28 January 2000

\begin{abstract}
Annual, seasonal and semiannual variations of F2-layer electron density $(N \mathrm{mF} 2)$ and height $(h \mathrm{mF} 2)$ have been compared with the coupled thermosphereionosphere-plasmasphere computational model (CTIP), for geomagnetically quiet conditions. Compared with results from ionosonde data from midlatitudes, CTIP reproduces quite well many observed features of $N \mathrm{mF} 2$, such as the dominant winter maxima at high midlatitudes in longitude sectors near the magnetic poles, the equinox maxima in sectors remote from the magnetic poles and at lower latitudes generally, and the form of the month-to-month variations at latitudes between about $60^{\circ} \mathrm{N}$ and $50^{\circ} \mathrm{S}$. CTIP also reproduces the seasonal behaviour of $\mathrm{NmF} 2$ at midnight and the summer-winter changes of $h \mathrm{mF} 2$. Some features of the F2-layer, not reproduced by the present version of CTIP, are attributed to processes not included in the modelling. Examples are the increased prevalence of the winter maxima of noon $\mathrm{NmF} 2$ at higher solar activity, which may be a consequence of the increase of F2-layer loss rate in summer by vibrationally excited molecular nitrogen, and the semiannual variation in $h \mathrm{mF} 2$, which may be due to tidal effects. An unexpected feature of the computed distributions of $\mathrm{NmF} 2$ is an east-west hemisphere difference, which seems to be linked to the geomagnetic field configuration. Physical discussion is reserved to the companion paper by Rishbeth et al.
\end{abstract}

Key words: Atmospheric composition and structure (thermosphere-composition and chemistry) -

Ionosphere (mid-latitude ionosphere; modelling and forecasting)

\section{Introduction}

\subsection{F2-layer anomalies}

This work discusses the F2-layer "anomalies", the term being generally taken to mean any departure from simple solar-controlled behaviour. These phenomena were detected in the 1930s and were well described by the end of the 1950s; for historical details see Rishbeth (1998). The principal anomalies observed at midlatitudes may be characterized as follows:

Winter or seasonal anomaly: $N \mathrm{mF} 2$ is greater in winter than in summer by day, but the anomaly disappears at night, $N \mathrm{mF} 2$ being greater in summer than in winter;

Semiannual anomaly: $\mathrm{NmF} 2$ is greater at equinox than at solstice;

Annual or non-seasonal anomaly: in the world as a whole December $N \mathrm{mF} 2$ is on average greater than June $\mathrm{NmF} 2$, both by day and by night. An alternative description is that the seasonal anomaly is greater in the Northern than the Southern Hemisphere. Among the observational papers about $N \mathrm{mF} 2$ in the literature, those of Yonezawa and Arima (1959) and Yonezawa $(1971,1972)$ are particularly extensive. Using data from many ionosonde stations, these authors give a detailed picture of the anomalies in noon and midnight $N \mathrm{mF} 2$ and of how they vary with latitude and solar activity. To give a very broad summary for midlatitudes at moderate solar activity: the annual anomaly in $N \mathrm{mF} 2$ is about $( \pm) 20 \%$, the semiannual anomaly about $( \pm)$ 15-20\%. The noon seasonal anomaly is more complicated; it is about $15 \%$ at midlatitudes and moderate solar activity, but it increases markedly with both latitude and solar activity and almost disappears at low solar activity.

Figures 1 and 2 illustrate the winter and semiannual anomalies at six midlatitude stations in different longitude sectors, for moderate and high levels of solar 


\section{$\mathrm{NmF2}$}

local noon
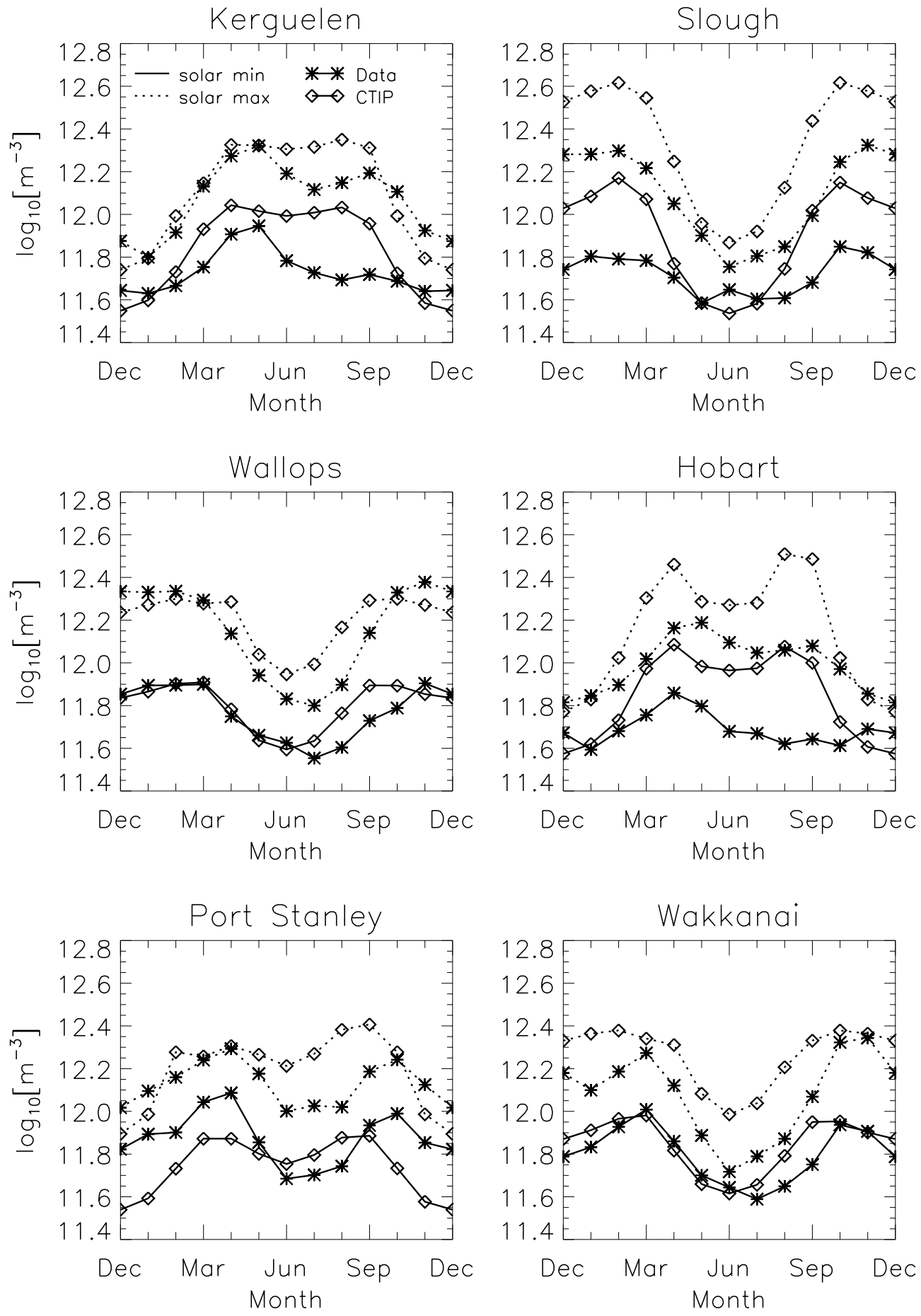

Fig. 1. Monthly mean ionosonde data for noon for six stations, plotted as asterisks. The values are averages over groups of years representing solar minimum $(1961 / 2 / 6 / 73 / 84$, mean $F_{10.7}=98:$ solid lines $)$ and solar maximum (1957-9/79-81/ 9/90, mean $F_{10.7}=208$ : dotted lines). The diamonds show CTIP values for $F_{10.7}=100$ (solid lines) and $F_{10.7}=180$ (dotted lines). For Kerguelen only the years from 1966 to 1984 are available, one or two years are omitted for some other stations

activity. The ionosonde data, in the form of monthly medians for groups of years, are shown by asterisks; the model values (CTIP), shown by diamonds, are discussed in Sect. 3.9. The ionosonde data are averages over several years with mean $F_{10.7} \approx 100$ and $F_{10.7} \approx 200$, as detailed in the figure caption. Taking "pole" to mean magnetic pole, we classify the stations by whether they are in "near-pole" longitudes, which are the North
Atlantic (European/North American) sector in the Northern Hemisphere and the Australasian sector in the Southern Hemisphere; or in the opposite "far-frompole" longitudes, which are the East Asian and South Atlantic sectors:

1. Near pole, high midlatitude: Slough $\left(52^{\circ} \mathrm{N}, 1^{\circ} \mathrm{W}\right)$, Kerguelen $\left(49^{\circ} \mathrm{S}, 70^{\circ} \mathrm{E}\right)$ 


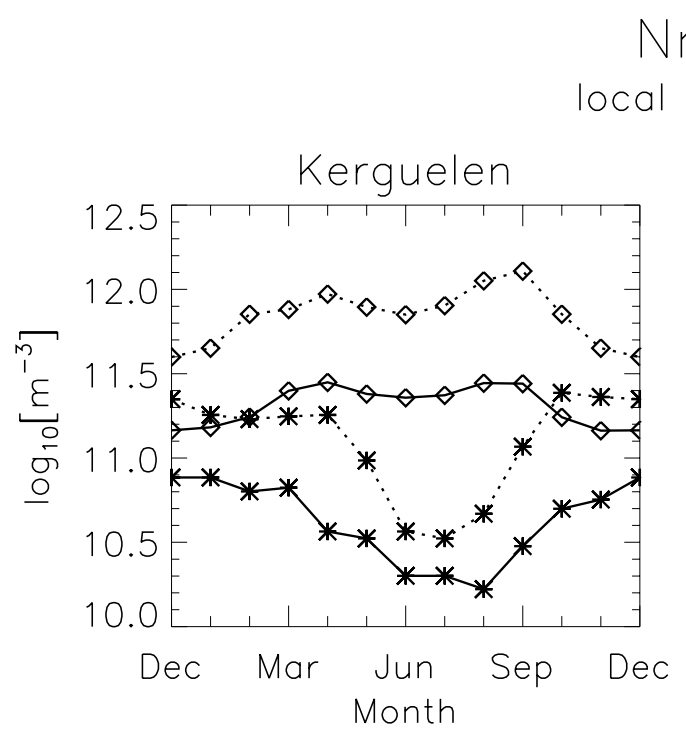

NmF2

ocal midnight
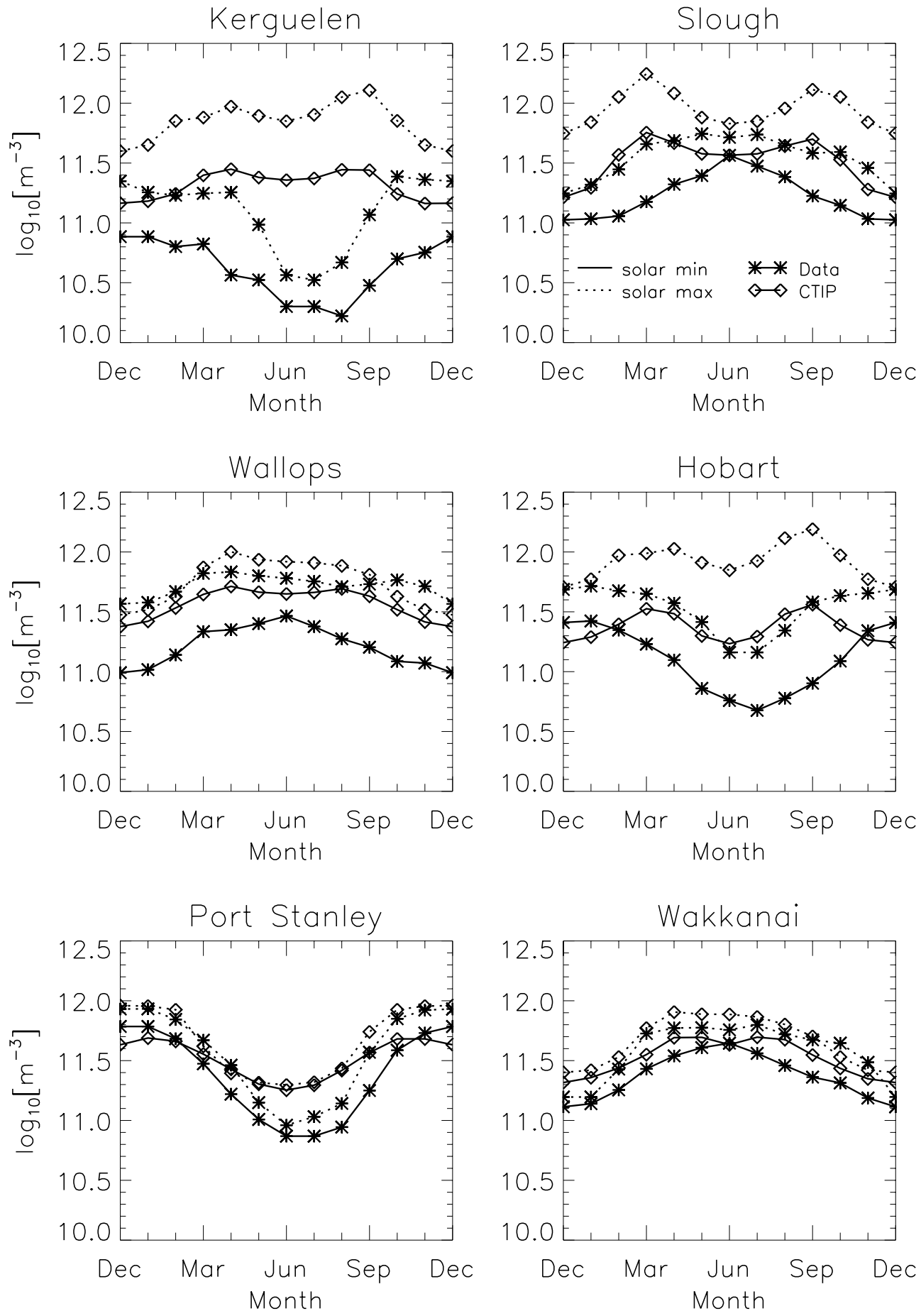

Fig. 2. As Fig. 1, for midnight

2. Near pole, lower midlatitude: Wallops Island $\left(38^{\circ} \mathrm{N}\right.$, $\left.75^{\circ} \mathrm{W}\right)$, Hobart $\left(43^{\circ} \mathrm{S}, 147^{\circ} \mathrm{E}\right)$

3. Far from pole: Wakkanai $\left(38^{\circ} \mathrm{N}, 142^{\circ} \mathrm{E}\right)$, Port Stanley $\left(52^{\circ} \mathrm{S}, 58^{\circ} \mathrm{W}\right)$.

Figure 1 for noon shows that all northern stations (Slough, Wallops, Wakkanai) have a seasonal anomaly, with $N \mathrm{mF} 2$ greater in midwinter than in midsum- mer, which is more marked at solar maximum than at solar minimum. The same applies at Hobart and Kerguelen at solar maximum, but at solar minimum winter and summer $N \mathrm{mF} 2$ are nearly equal. At Port Stanley, summer and winter $\mathrm{NmF} 2$ are almost equal at solar maximum, while at solar minimum the seasonal anomaly is absent. This can be regarded as an effect of the annual or non-seasonal anomaly, which 
opposes the seasonal anomaly in the southern hemisphere.

None of the stations has a purely summer/winter pattern. All show evidence of a semiannual component, most noticeably Port Stanley and Wakkanai which are in "far-from-pole" sectors. In the "near-pole" sectors, Kerguelen and Hobart in the south and Wallops and Slough in the north (also Moscow, not shown, which closely resembles Slough but is $30^{\circ}$ to the east), greatest $N \mathrm{mF} 2$ occurs on the winter side of equinox, giving a rather flat variation centred on winter solstice. $N \mathrm{mF} 2$ is slightly greater in autumn than in spring, particularly in the south.

Figure 2 for midnight shows that summer $\mathrm{NmF} 2$ exceeds winter $N \mathrm{mF} 2$ at all stations. The semiannual variation is clear at solar maximum at northern stations (Slough, Wallops, Wakkanai); elsewhere its
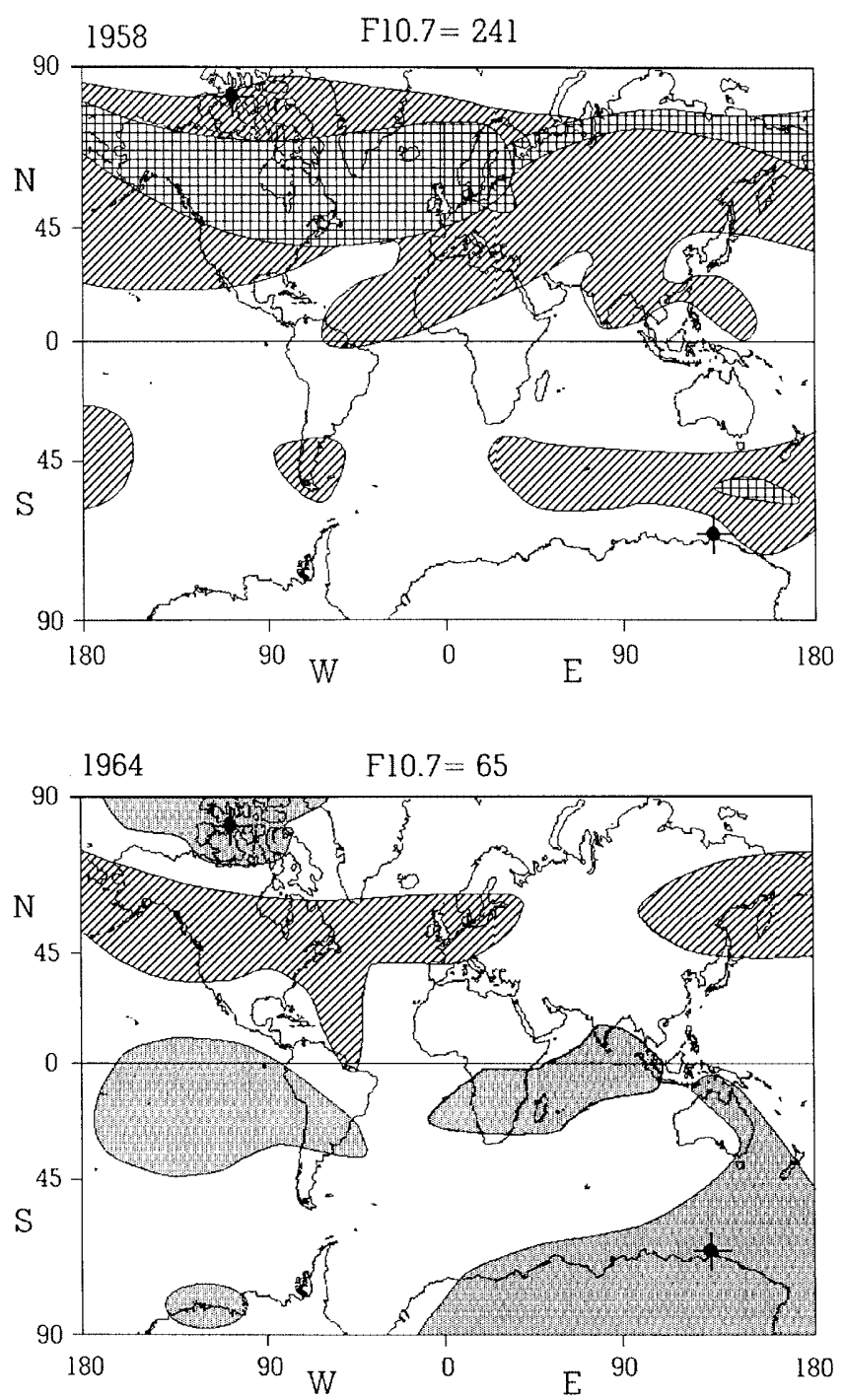

Fig. 3. Annual and semiannual effects in noon critical frequency $f_{\mathrm{OF}} 2$, simplified from Torr and Torr (1973). The shading shows "Maximum summer" domains (where summer $f_{\mathrm{oF}} 2$ exceeds winter and equinox $f_{\mathrm{oF}}$ ), i.e. no seasonal anomaly, and "Maximum winter" domains (where winter $f_{\mathrm{oF}} 2$ exceeds summer and equinox $f_{\mathrm{OF}}$ ), i.e. the seasonal anomaly exists. No shading means $f \mathrm{oF} 2$ is greatest contribution results in a rather flat summer maximum, though it is weak at Hobart and Port Stanley at solar minimum.

The maps of Fig. 3, adapted from Torr and Torr (1973), are based on data from a large number of ionosondes for three levels of solar activity. They show where noon $f_{\mathrm{oF}} 2$ (proportional to $\sqrt{N \mathrm{mF} 2}$ ) is greatest in summer, or at equinox, or in winter. Two levels of "winter anomaly" are shown. The obvious midlatitude feature is the belt of strong winter maximum at high northern midlatitudes, strongest at high solar activity (top-left map), with a weaker belt in the Australasian sector. Low latitudes and southern midlatitudes show a semiannual variation. At low solar activity (bottom map), no seasonal anomaly exists in the cross-hatched regions, because $N \mathrm{mF} 2$ is greatest in summer. These regions are mostly south of the equator, which is an indication of the
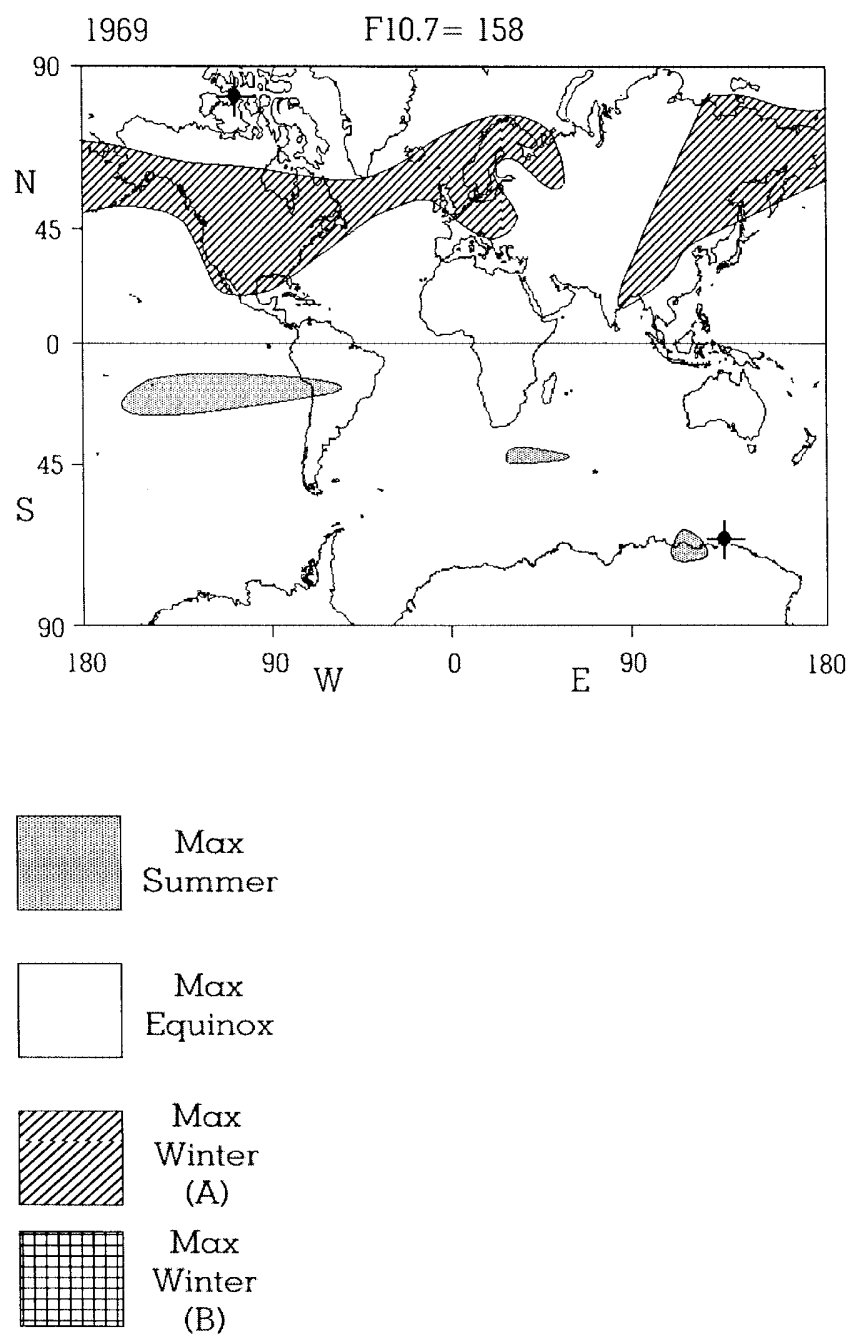

at equinox, i.e. "semiannual anomaly". The "Maximum winter" domains are divided according to whether the difference (winter $f_{\mathrm{OF} 2}$ - equinox $f_{\mathrm{OF}}$ ) is less than $2 \mathrm{MHz}(A)$ or greater than $2 \mathrm{MHz}$ $(B)$. Crosses on black spots mark the positions of the magnetic dip poles (Rishbeth, 1998) 
annual (non-seasonal) anomaly. Being based on the sign of the (winter-summer), (winter-equinox) and (summerequinox) differences, the maps tend to oversimplify the situation; furthermore, they do not clearly distinguish areas of no data, and their accuracy is affected by the uneven global distribution of stations.

\subsection{Theories of the anomalies}

An obvious possible cause of the annual anomaly is the $3 \%$ variation in Sun-Earth distance, though the resulting $6 \%$ variation in the flux of solar ionizing radiation is insufficient to account for the reported annual anomaly of $10-20 \%$ in $N \mathrm{mF} 2$. Buonsanto (1986) suggested that the varying Sun-Earth distance has proportionally greater effect on F2-layer electron density, its direct effect being amplified by a variation in the atomic oxygen/molecular oxygen ratio in the neutral air, which is due to the concomitant variation in the photodissocation of molecular oxygen.

The F2-layer seasonal anomaly has been attributed to temperature changes (Appleton, 1935), and the interhemispheric transport of ionization (Rothwell, 1963); but it is now generally accepted that its main cause is a seasonal change in chemical composition (the atomic/molecular ratio) of the neutral air, much as suggested by Rishbeth and Setty (1961). Duncan (1969) extended this theory with the idea that the composition changes are produced by a global summer-to-winter thermospheric circulation. Experimental evidence concerning the composition changes was obtained by means of incoherent scatter radar (Cox and Evans, 1970; Evans and Cox, 1970; Waldteufel, 1972; Alcaydé et al., 1974) and rockets and satellites (Offermann, 1974; Prölss and von Zahn, 1974; Mauersberger et al., 1976), and the circulation theory was eventually verified by global modelling (Fuller-Rowell and Rees, 1983).

Explaining the semiannual variation in $N \mathrm{mF} 2$ is more difficult. In his original paper on the subject, Burkard (1951) suggested that solar EUV emission is anisotropic, so that the flux reaching the Earth varies with the Earth's heliographic latitude in such a way that it maximizes at the equinoxes, but he gave no evidence to support his idea. Other semiannual phenomena, reviewed by Ivanov-Kholodnii (1973), need to be mentioned because they might, in principle, be related to the equinox maxima in $N \mathrm{mF} 2$. They are the equinox maxima in the F2 peak height $h \mathrm{mF} 2$ (Becker, 1967), in the neutral air density, as detected from the orbital perturbations of artificial satellites (Paetzold and Zschörner, 1961), and in geomagnetic activity. Possible links to the semiannual oscillations in the lower and middle atmosphere also need to be considered.

There are several theories for the global semiannual variation in neutral density, some of which have implications for the variation of $N \mathrm{mF} 2$. Two of the theories rely on external forcing of the upper atmosphere. Lal (1992, 1998) attributed the semiannual variations in neutral density and $\mathrm{NmF} 2$ to the influence of the solar wind.
Walterscheid (1982) relied on a semiannual variation in Joule heating, a natural consequence of the semiannual variation in geomagnetic activity (Russell and McPherron, 1973), to support his conduction mode theory. The third theory (Fuller-Rowell, 1998) invoked the idea of increased internal thermospheric mixing at solstice to explain the semiannual variation in neutral density. The same mixing process causes a globally averaged variation in $\mathrm{NmF} 2$.

Another internal mechanism was proposed by Millward et al. (1996a) to explain the longitude differences in seasonal and semiannual characteristics at southern midlatitudes. It depends on the large offset of the geomagnetic and geographic poles in the south, together with variations of solar zenith angle. It is with the mechanisms of Fuller-Rowell (1998) and Millward et al. (1996a) that the present papers are mostly concerned.

\subsection{Purpose and plan of the study}

Much of the progress in understanding the F2-layer has come from the development of global models of the thermosphere and ionosphere, particularly those that compute the variations of chemical composition of the neutral air (e.g. Fuller-Rowell and Rees, 1983; Dickinson et al., 1984). Our purpose here is to apply one such model, the coupled thermosphere-ionosphere-plasmasphere model (CTIP) of Fuller-Rowell et al. (1996) and Millward et al. (1996b), to the study of the global quietday F2-layer, and to discuss the model's success in reproducing various observed phenomena. A major objective is to see how far the semiannual anomaly, particularly, can be explained by the global thermospheric circulation without invoking other causes, in line with the theory of Millward et al. (1996a).

In the present work, Sect. 2 describes the modelling, with details of the version of CTIP (Sect. 2.1), definitions of latitude zones (Sect. 2.2), and assumptions regarding the geomagnetic field and auroral ovals (Sect. 2.3), electric fields (Sect. 2.4), and tidal modes (Sect. 2.5). The results are described in Sect. 3 which deals in turn with noon $N \mathrm{mF} 2$ (Sect. 3.1) and its variation with solar activity (Sect. 3.2), night NmF2 (Sect. 3.3), monthto-month morphology of $\mathrm{NmF} 2$ (Sect. 3.4), the height hmF2 (Sect. 3.5), the equatorial F2-layer (Sect. 3.6), and the annual and semiannual Fourier components of $N \mathrm{mF} 2$ and $h \mathrm{mF} 2$ (modelling in Sect. 3.7, comparison with ionosonde data in Sects. 3.8 and 3.9). Section 4 deals with the possible effects of semidiurnal tides (Sect. 4.1) and vibrationally excited nitrogen (Sect. 4.2). The CTIP modelling is "scored" in Sect. 5, by listing which of the observed F2-layer phenomena are, or are not, accounted for. The relation between the global thermospheric circulation, vertical motions and composition changes has been discussed by Rishbeth and MüllerWodarg (1999). Further discussion of chemical composition, winds, and electric fields may be found in the companion Paper II (Rishbeth et al., 2000a). The variations of height $h \mathrm{mF} 2$ are further discussed by Rishbeth et al. (2000b). 


\section{Computations with CTIP}

\subsection{Modelling with CTIP}

The modelling was done with the coupled thermosphere-ionosphere-plasmasphere model CTIP described by Fuller-Rowell et al. (1996), Millward et al. (1996b) and Field et al. (1998). The auroral particle precipitation pattern was taken from Fuller-Rowell and Evans (1987) and Evans et al. (1998), at an activity level corresponding to $K p=2+(A p \approx 9)$, the highlatitude electric convection field from Foster et al. (1986), and the low-latitude electric field pattern from Richmond et al. (1980). The version used does not incorporate such refinements as nitric oxide chemistry or the effects of vibrationally excited species. The thermospheric part of the program computes the parameters of the neutral air and ionized plasma with a 1-min time step on a global grid, $2^{\circ}$ in latitude $\times 18^{\circ}$ in longitude. In the vertical direction, the parameters are computed at 15 pressure-levels, $Z=1-15$, spaced at vertical intervals of one scale height from the base of the thermosphere at level $Z=1$, taken to be at real height $h=80 \mathrm{~km}$. The real height $h$ of level $Z$ is given by

$h(Z)=\int H(Z) \mathrm{d} Z+80(\mathrm{~km})$

in which $H$ is the atmospheric scale height and the integration goes from $Z=1$ up to the level in question. For example, level $Z=7$ at $127 \mathrm{~km}$ is at the top of the E-layer, and the F1-layer is at $Z=9-10(160-190 \mathrm{~km})$. For moderate solar activity $\left(F_{10.7}=100\right)$, the midlatitude $\mathrm{F} 2$ peak lies generally at about $Z=11.5(260 \mathrm{~km})$ by day and $Z=14(330 \mathrm{~km})$ by night, and about 100 $\mathrm{km}$ higher for $F_{10.7}=180$. The concentrations, temperatures and velocities of neutral and ionized constituents are output at intervals of $1 \mathrm{~h}$.

To achieve a stable solution, the model was run on a SPARC-10 system for 20 simulated days for each month, with conditions held at the 21st of each month. During the settling-down of the model to a steady daily variation, the neutral gas composition is slowest to settle so, as the ion density settles down much more quickly, the time-consuming plasmaspheric routine is introduced only for the last three days of each 20-day simulation. Because of the month-by-month computing procedure, the outputs for July are almost the same as for May; the same applies to August and April, to September and March, to October and February, and to November and January. The available runs are as follows:

1. Monthly "standard" runs at $F_{10.7}=100$, for 21 December, 21 January, 21 February, ... 21 December

2. Monthly runs at $F_{10.7}=180$, for 21 December, 21 January, ... 21 June

3. Monthly runs to investigate the effect of imposed semidiurnal tidal motions (Sect. 4.1)

4. A few runs at $F_{10.7}=100$ with no imposed electric field at middle and low latitudes (Sect. 2.4).
For the modelling at $F_{10.7}=180$, the EUV fluxes are multiplied by a factor of 1.8 from the values used for $F_{10.7}=100$, the appropriate temperature dependence being included in parameters such as rate coefficients. This scaling is based on the approximate linear dependence of EUV flux on $F_{10.7}$ over this range of solar activity, as shown by Hinteregger et al. (1981) and Richards et al. (1994a). This approach is simplistic, but the main object of changing the EUV flux was to see whether this would reproduce the observed solar cycle variation in the annual and semiannual amplitudes in $N \mathrm{mF} 2$, and it seemed unlikely that using a more sophisticated model of the solar cycle variation would give any more physical insight. No change with $F_{10.7}$ is made to the Schumann-Runge ultraviolet continuum (which is important for dissociation of molecular oxygen), the high-latitude particle precipitation or the electric field pattern. In terms of the sunspot number $R$, the values $F_{10.7}=100$ and 180 approximately correspond to $R=50$ and 133 .

In the calculations, the Sun-Earth distance is assumed fixed at $1 \mathrm{AU}$, so the ionizing flux incident at the top of the atmosphere remains constant. One obvious but quite small cause of annual variation is therefore excluded, so to that extent the model is not realistic; but on the other hand, the calculations should reproduce any annual variation that might originate within the thermosphere itself. Within the time available, it was not feasible to do two sets of runs, with fixed and with varying Sun-Earth distance, to investigate the theory of Buonsanto (1986) referred to in Sect. 1.2: as pointed out in Sect. 3.9, this effect is not particularly important in our results. Given the limitations of computing time, it was not possible to do any "tuning" of CTIP, to see what changes of the model might produce better or worse agreement with actual data. This work concentrates on describing noon and midnight values of the peak electron density $N \mathrm{mF} 2$ and the height $h \mathrm{mF} 2$, and is concerned with relative rather than absolute values of NmF2.

\subsection{Latitude zones}

The latitude zones referred to are defined in terms of magnetic latitude, as follows:

Equatorial: the zone within about $20^{\circ}$ of magnetic equator, in which F2-layer behaviour is strongly influenced by the low-latitude system of electric fields. Not discussed in detail here;

Midlatitudes: zones between magnetic equatorial zone and auroral ovals, divided at roughly $45^{\circ}$ magnetic latitude into "lower" and "higher" midlatitudes. The work focuses on these zones;

Auroral ovals: belts $10-15^{\circ}$ wide, the low latitude boundary being at about $75^{\circ}$ magnetic latitude at noon, and $66^{\circ}$ magnetic latitude at midnight;

Polar caps: regions poleward of the auroral ovals. 


\subsection{Geomagnetic field model}

CTIP uses a geomagnetic field model, with offset poles at geographic positions $81^{\circ} \mathrm{N}, 78^{\circ} \mathrm{W}$ and $74^{\circ} \mathrm{S}, 126^{\circ} \mathrm{E}$. The poles are surrounded by the eccentric auroral ovals, which are belts about $10^{\circ}-15^{\circ}$ wide that receive energy from electric fields and energetic particles generated by magnetospheric processes. These auroral inputs are taken from the Tiros/NOAA precipitation maps that are keyed to an "auroral power index" (Fuller-Rowell and Evans, 1987; Evans et al., 1988). We have chosen an auroral power index of 5 corresponding to $K \mathrm{p}=2+(A \mathrm{p} \approx 9)$; these inputs remain unchanged throughout the year and with solar activity. The lowlatitude boundaries (equatorward edges) of the ovals, which play an important part in determining the thermospheric circulation, lie at about $75^{\circ}$ magnetic latitude at noon and $66^{\circ}$ magnetic latitude at midnight. The longitude variations of the auroral ovals are important, because the magnetic field configuration is the only longitude-dependent feature of CTIP.

Because of the offsets of the magnetic poles, the corresponding geographic latitudes vary by about $\pm 8^{\circ}$ in north and $\pm 15^{\circ}$ in the south, as shown in Fig. 4 which is drawn in geographic coordinates, the magnetic poles being marked by stars. The four curves in each hemisphere represent the situation at four Universal Times (the southern 18 UT curve is rather uncertain around $90^{\circ} \mathrm{W}$, because the auroral oval passes over the geographical pole).

\subsection{Electric field models}

The ionosphere is permeated by electrostatic fields, which influence the electron distribution in the F2-layer. CTIP uses electric field distributions taken from empirical models. For auroral and polar regions, this is the statistical model of Foster et al. (1986), for fairly quiet

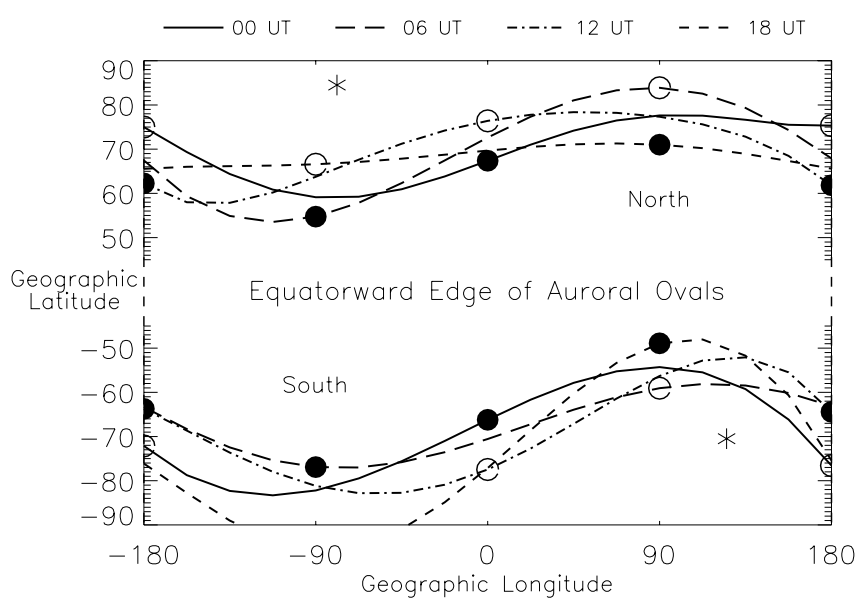

Fig. 4. Geographic latitudes and longitudes of the equatorward edge of the auroral ovals in the CTIP model, for low magnetic activity $(K \mathrm{p}=2+)$ : Northern Hemisphere (above), Southern Hemisphere (below), at $00 \mathrm{UT}$ (solid curves), $06 \mathrm{UT}$ (long dashes), 12 UT (dash-dot curves) and 18 UT (short dashes). Stars mark the positions of the magnetic poles geomagnetic conditions $(K \mathrm{p}=2+)$, with no seasonal or solar cycle variations. This field does not appear to have a significant influence on the quiet-day-F2-layer at midlatitudes, so its details are not important to the present work. At middle and low latitudes, the CTIP electric field distribution is taken from the model of Richmond et al. (1980), which includes some seasonal variation but no solar cycle variation. These electric fields strongly influence the F2-layer in the equatorial zone, but are not of great importance at midlatitudes. In the "no electric field" runs mentioned in Sect. 2.1, the polar "Foster" fields are kept on at all times, but the mid/low latitude "Richmond" electric fields are switched off, so at these latitudes the charged particles are not subject to electrodynamic drift. The changes to the electron distribution are briefly described in Sects. 3.6 and 3.7, and the implications for the physics are deferred to Sect. 5 of Paper II.

\subsection{Tidal model}

An additional series of simulations was made to investigate whether the semiannual variation in tidal forcing affects the semiannual patterns in the $\mathrm{F}$ region. For each month, a different value of tidal amplitudes and phases was chosen, based on the climatological study by Forbes and Vial (1989). The principal diurnal modes originate within the thermosphere and are included in CTIP. There are also diurnal modes (e.g. the 1,1 mode) which propagate into the lower thermosphere from below, but they are not included in this particular study.

The semidiurnal tides are imposed in CTIP by forcing the height of the lower boundary pressure level $(Z=1$, height $80 \mathrm{~km}$ ) to oscillate globally, with the latitudinal structure defined by a series of Hough functions. The resulting oscillations of temperature and wind are calculated self-consistently at the lower boundary, using analytical relations from classical tidal theory (Holton, 1975). Table 1 shows amplitudes in metres and phases (month of maximum) of the four semidiurnal propagating Hough modes at the $80 \mathrm{~km}$ boundary.

The $(2,2)$ mode is the strongest of the Hough modes and the $(2,4)$ mode is the second strongest. Their amplitudes have a weak annual variation and a stronger semiannual variation, the maximum being at solstice for the $(2,2)$ mode and at equinox for the $(2,4)$ mode, so there is some cancellation. The $(2,4)$ mode extends to higher latitudes than does the $(2,2)$ mode. The antisymmetrical $(2,3)$ and $(2,5)$ modes are weaker than the symmetrical modes.

Table 1. Amplitudes (in geopotential height, m) and month of maximum of tidal components

\begin{tabular}{lrll}
\hline Mode & Mean & Annual & Semiannual \\
\hline$(2,2)$ & 257 & 38 (December) & 72 (December) \\
$(2,3)$ & 54 & 18 (December) & 23 (January) \\
$(2,4)$ & 94 & 32 (February) & 69 (March) \\
$(2,5)$ & 71 & 16 (November) & 34 (January) \\
\hline
\end{tabular}


These semidiurnal tides impose a complex forcing in the lower thermosphere, of up to several hundred metres in all, with an appreciable semiannual component. However, the present version of CTIP does not consider the electrodynamic effect of these tides, because the low latitude E-region electric fields are taken from an empirical model (Sect. 2.4), instead of being computed self-consistently with the winds. The tidal simulations, therefore, may not accurately represent the considerable amounts of momentum and energy deposited in the E-region by the full dynamo process.

\section{Results}

\subsection{Overall patterns of $\mathrm{NmF2}$ at noon}

Figure 5 shows the global distributions of $N \mathrm{mF} 2$ in December, March and June. The first thing to notice is the geomagnetic alignment: the contours tend to follow the geomagnetic equator and the low-latitude boundaries of the auroral ovals. At noon (top row of Fig. 5), there is also geographic control, noticeably in high winter latitudes where $N \mathrm{mF} 2$ cuts off sharply at the daynight terminator at latitude $67^{\circ}$, any ionization at higher latitudes being auroral. Below $67^{\circ}$ the winter ionosphere is in daylight at noon, and $N \mathrm{mF} 2$ is greater than in the summer hemisphere, the equinox pattern is more symmetrical about the equator. The equatorial trough is clearly seen; in March it is symmetrical but at the solstices it is lopsided, with a markedly higher crest on the winter side.

The regions of largest winter $\mathrm{NmF} 2$ occur around latitudes $60^{\circ} \mathrm{N}$ and $50^{\circ} \mathrm{N}$, as in the maps of Torr and Torr (1973), at least for high and moderate solar activity. They lie in "near-pole" longitudes, $30^{\circ} \mathrm{W}-$ $30^{\circ} \mathrm{E}$ in the north in December, somewhat to the east of the corresponding maxima in the maps of Fig. 3, and $120^{\circ} \mathrm{E}-160^{\circ} \mathrm{W}$ in the south in June. In "far-from-pole" longitudes, the winter/summer difference is less marked and $N \mathrm{mF} 2$ is greatest at equinox.

The maps show a east-west longitude difference in $N \mathrm{mF} 2$ at midlatitudes $\left(30^{\circ}-50^{\circ}\right.$ approximately), with noon $N \mathrm{mF} 2$ greater in eastern longitudes than in western. This feature is most noticeable in March, but appears too as weak enhancements around $60^{\circ} \mathrm{E}$, in December in the north and June in the south. In CTIP, longitude differences can arise only from the geomagnetic field, so the positions of the auroral ovals are important to the interpretation. This topic is discussed in more detail in Paper II. As the month-by-month approach described in Sect. 2.1 produces little difference between the two equinoxes (which would not necessarily be the case with day-by-day calculations), the September and March distributions are very similar. The transitions between northern and southern solstice conditions occur quite rapidly from February to April and from August to October. The patterns at solstice are fairly stable for some months, there being little change from November to February and from April to August. In
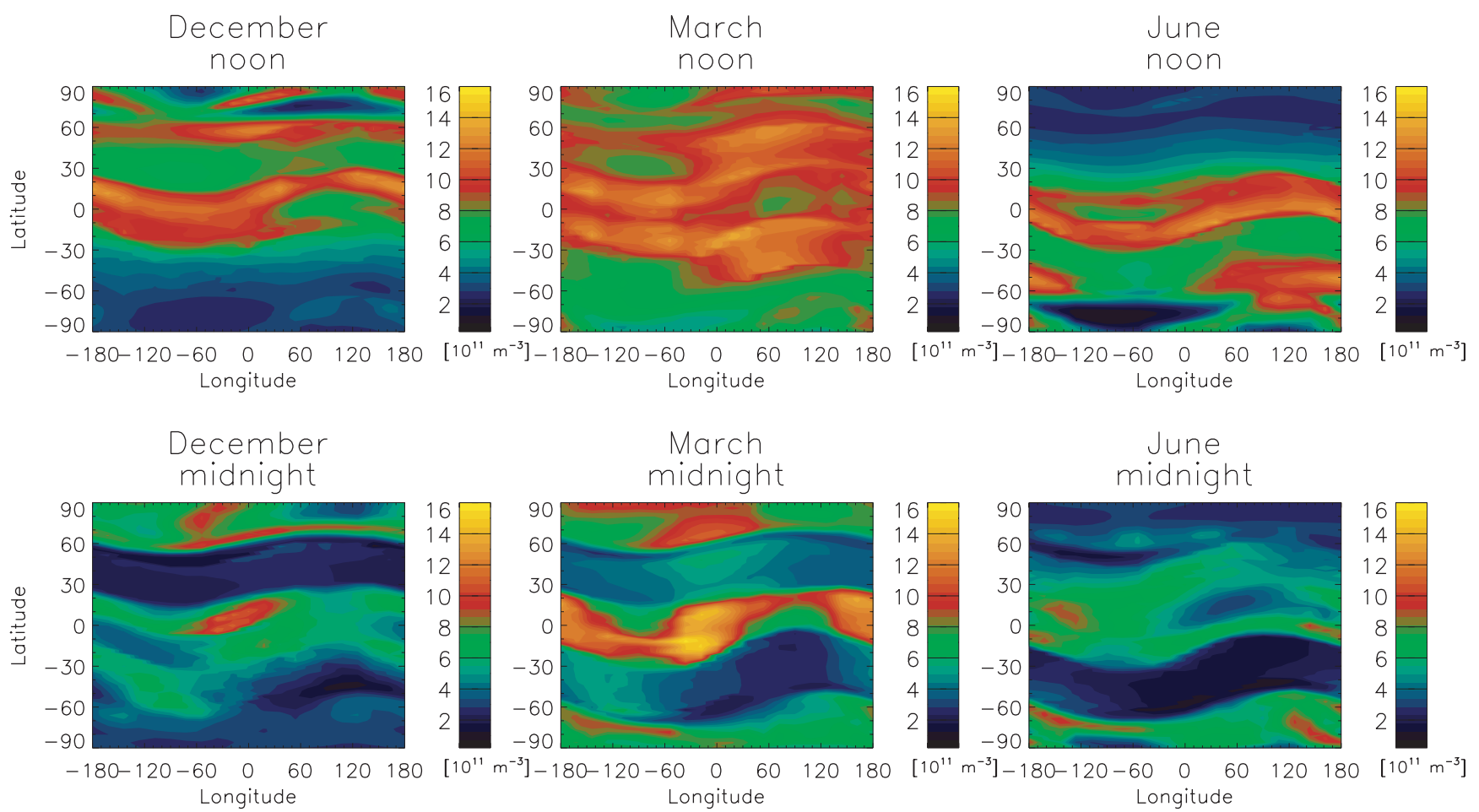

Fig. 5. Noon and midnight maps of $N \mathrm{mF} 2$ in December, March, June, $F_{10.7}=100$ 
high winter latitudes, the small month-to-month changes of solar zenith angle make a big difference to noon $N \mathrm{mF} 2$; as a consequence, the greatest values of $N \mathrm{mF} 2$ occur not at winter solstice, but a month or so either side of it (Sect. 3.4).

\subsection{Variations with solar activity}

In most places, the increase of solar activity from $F_{10.7}=$ 100 to $F_{10.7}=180$ raises $N \mathrm{mF} 2$ by a factor of about 1.8 (as expected, since the model EUV flux $\propto F_{10.7}$ ). This is shown in Fig. 6 by the predominance of green tints which cover the range 1.5-2.1. In some places the factor is larger, reaching 2.5-3 at winter noon, at high midlatitudes in the "far-from-pole" sectors. Taking sunspot number $R=50$ to be equivalent to $F_{10.7}=100$ and $R=133$ to $F_{10.7}=$ 180 , the factor 1.8 fits the rule-of-thumb formula,

$N \mathrm{mF} 2 \propto(1+0.02 R)$,

(Allen, 1948), which is based on data from several ionosonde stations. The most likely reason why the ratio shown in Fig. 6 is not 1.8 everywhere is that, in CTIP, the solar EUV input is altered in proportion to $F_{10.7}$ but the high-latitude heating is not. The thermospheric circulation, that controls the seasonal changes (Rishbeth and Müller-Wodarg, 1999), is therefore not quite the same at the two levels of $F_{10.7}$. The present work does not discuss the "absolute calibration" of $N \mathrm{mF} 2$, which would require precise modelling of the input radiations with full account of wavelength dependence, not attempted in this study. Comparisons with ionosonde values of $N \mathrm{mF} 2$ are given in Sect. 3.9.

\section{$3.3 \mathrm{NmF2}$ at midnight and sunrise}

Figure 5 (bottom row) shows that the winter anomaly disappears and $\mathrm{NmF} 2$ is very small over most of the winter hemisphere, again as in the real F2-layer (Fig. 2). As at noon, the patterns have many details but basically they are geomagnetically aligned, though the equatorial trough has almost disappeared. Increasing solar activity from $F_{10.7}=100$ to $F_{10.7}=180$ generally raises $N \mathrm{mF} 2$ by a factor of 1.8 , as at noon, but by more in some places, notably the boundaries of the auroral ovals.

At high winter midlatitudes, $N \mathrm{mF} 2$ is very small at night and very large at noon. This is linked with the fact that the rate of increase near sunrise, $\mathrm{d}(N \mathrm{mF} 2) / \mathrm{d} t$, is much greater in winter than in summer, as is observed in the "seasonal sunrise anomaly" (Rishbeth and Setty, 1961).

\subsection{Months of peak noon $\mathrm{NmF2}$ versus latitude}

To determine the times of year at which $N \mathrm{mF} 2$ (or $f \mathrm{oF} 2$ ) is greatest, Burkard (1951) used ionosonde data from 32 stations for three years at solar maximum, 1947-9. King and Smith (1968) used data from 105 stations covering

CTIP
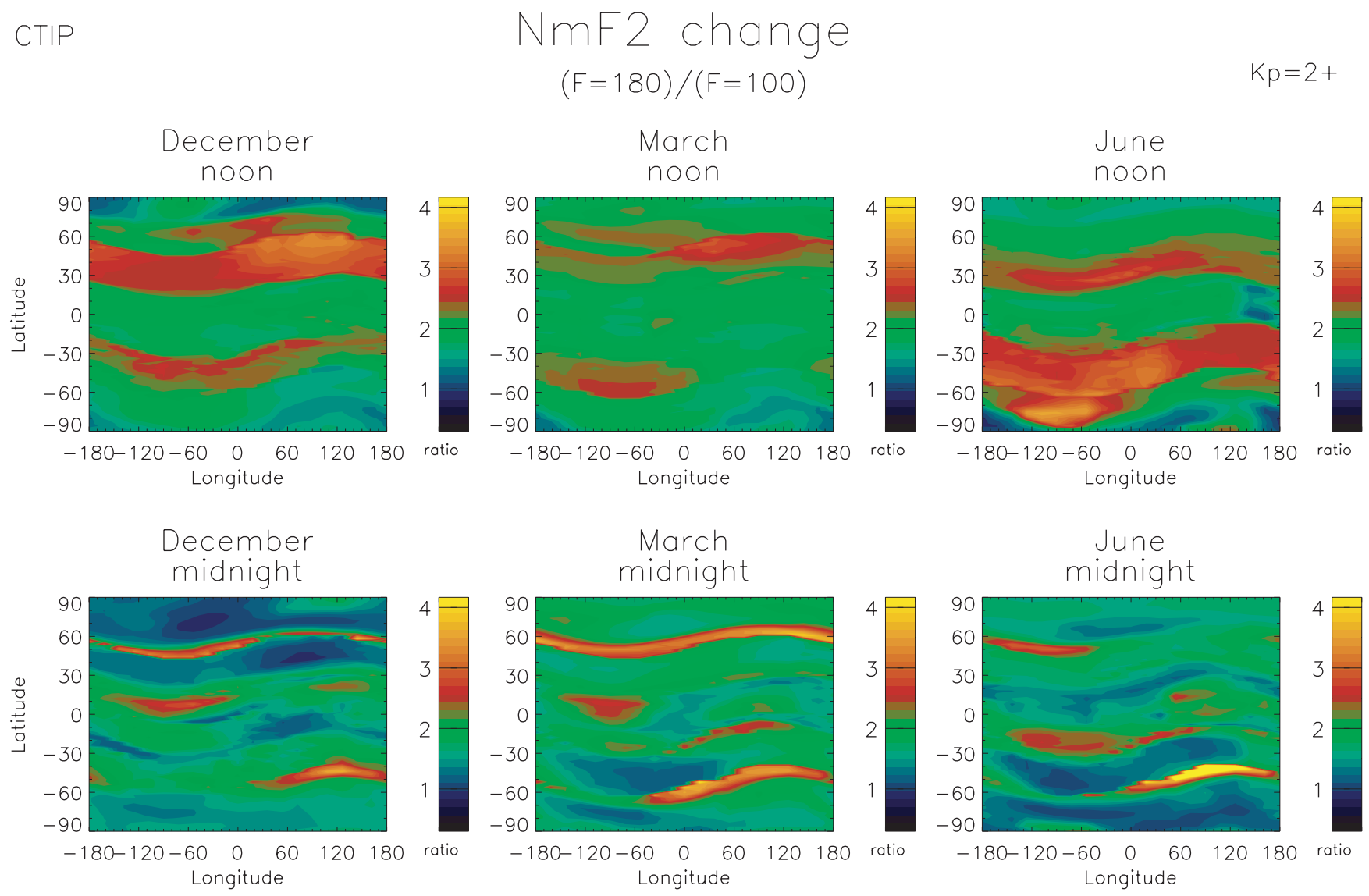

Fig. 6. Noon and midnight maps of ratio $\left\{\operatorname{NmF} 2\left(F_{10.7}=180\right) \div \operatorname{NmF} 2\left(F_{10.7}=100\right)\right\}$ in December, March, June 
the six years 1947-9/53-5, in two longitude sectors centred on $120^{\circ} \mathrm{E}$ and $60^{\circ} \mathrm{W}$. Both papers show that in high northern midlatitudes the peaks of noon $N \mathrm{mF} 2$ occur about two months apart, in November and January; this separation increases towards low latitudes, where $N \mathrm{mF} 2$ has a semiannual variation with equinoctial peaks. In southern latitudes the peaks converge towards May and July. There is little difference between the two longitude sectors studied by King and Smith, except for a slightly wider separation of the southern winter peaks at $60^{\circ} \mathrm{W}$ which corresponds to the predominant semiannual variation in this sector. Burkard did not separate his data by longitude.

Figure 7 shows the results of King and Smith (1968) (bold lines) superimposed on CTIP plots of $N \mathrm{mF} 2$ at almost the same longitudes, $126^{\circ} \mathrm{E}$ and $54^{\circ} \mathrm{W}$. The CTIP results generally fit the data quite well, except in high southern latitudes where the "model" maxima converge towards June but the "data" maxima stay at May and September. The same applies to Burkard's (1951) results (not shown here) which otherwise agree quite well with CTIP, especially at March equinox, not so well at September equinox. The dip in NmF2 in December (north) and June (south) is largely due to the large solar zenith angle at solstice, though strong poleward winds in winter play a part.

\subsection{The height of the F2 peak}

Figure 8 shows the global distributions of the real height of the F2-peak, $h \mathrm{mF}$, in December, March and June.
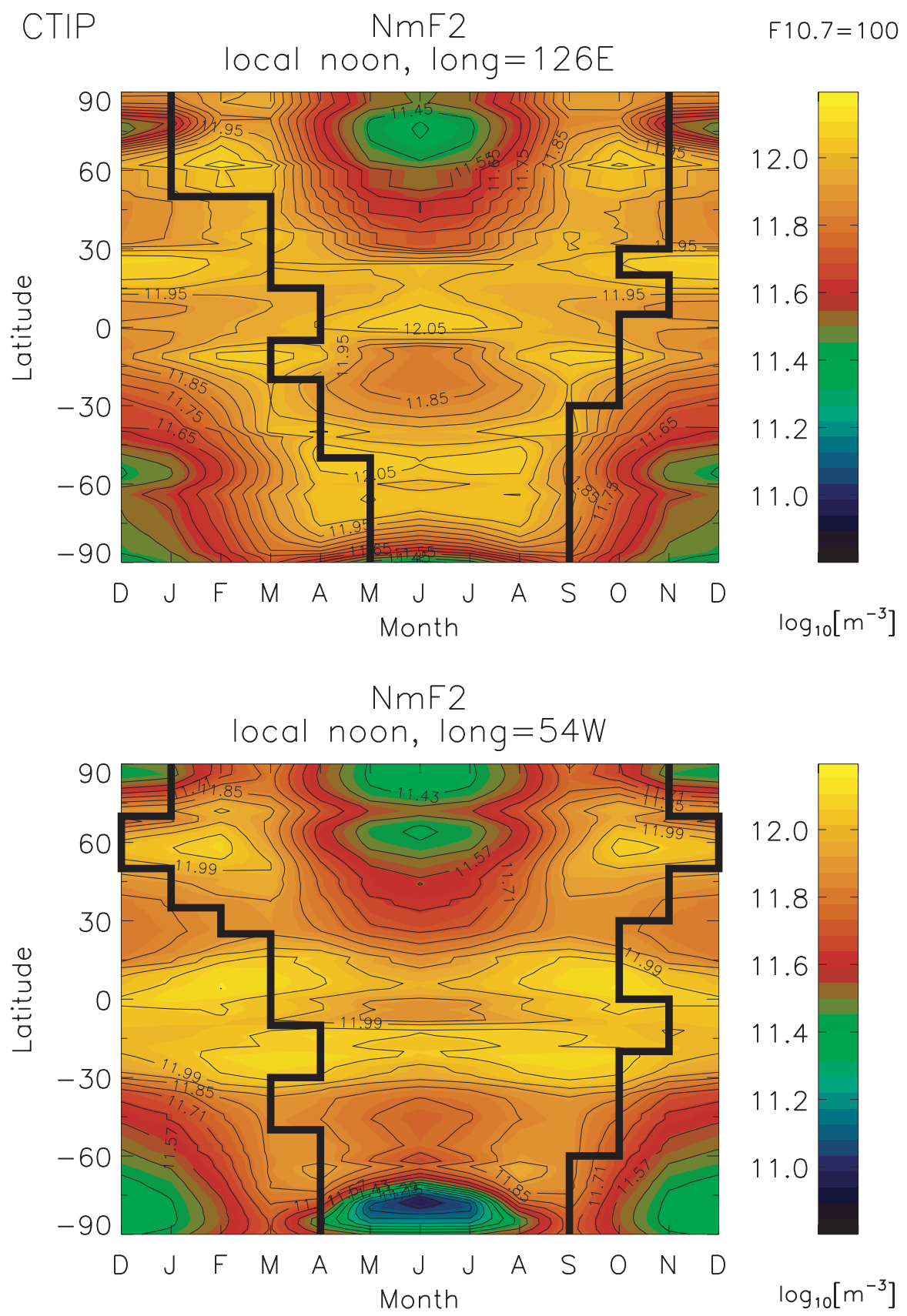

Fig. 7. Map of $\log N \mathrm{mF} 2$ at noon versus month at longitudes $126^{\circ} \mathrm{E} \& 54^{\circ} \mathrm{W}$, showing months of greatest noon $\mathrm{NmF} 2$ as found from ionosonde data by King and Smith (1968) 

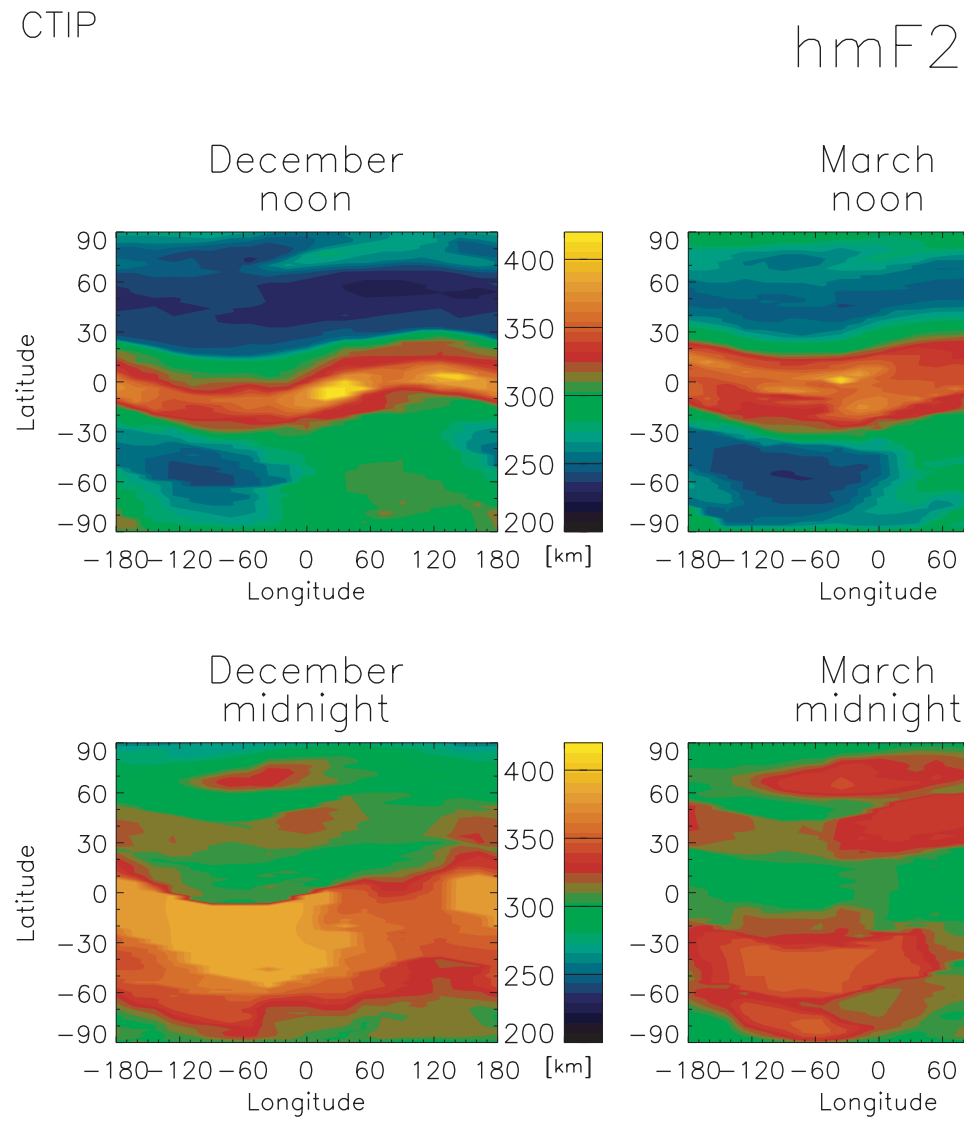
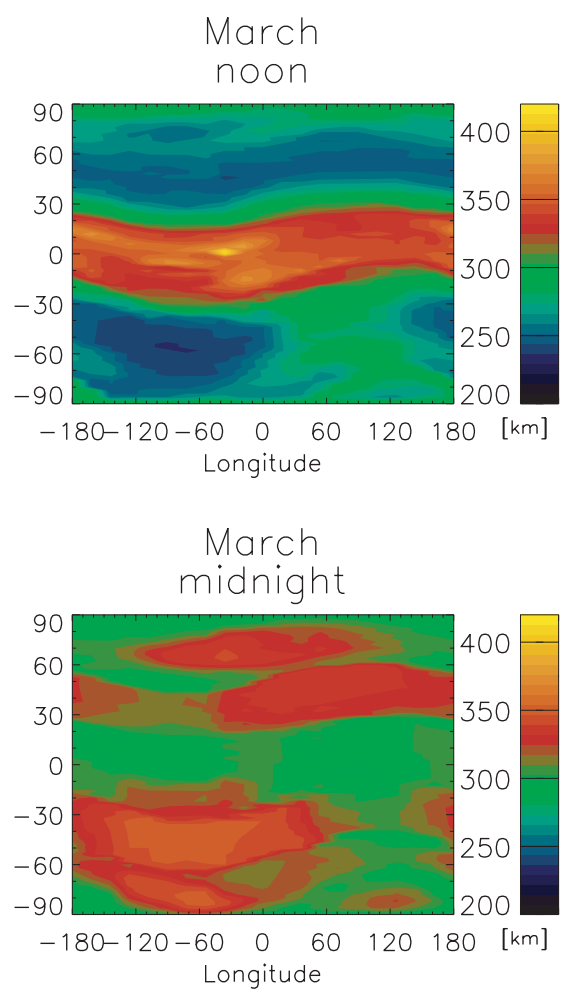

$F=100$

$\mathrm{Kp}=2+$
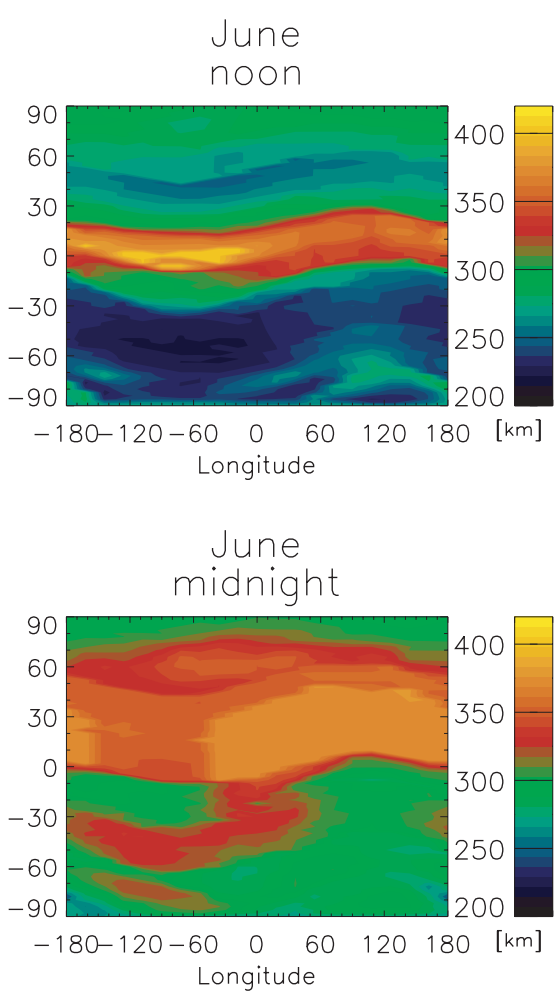

Fig. 8. Noon and midnight maps of $h \mathrm{mF} 2$ in December, March, June, $F_{10.7}=100$

As with $N \mathrm{mF} 2$, both day and night patterns are geomagnetically aligned. The modelled $h \mathrm{mF} 2$ is nearly symmetrical about the magnetic equator at March equinox, but at midlatitudes $h \mathrm{mF} 2$ is generally higher in summer $(240-300 \mathrm{~km}$ at noon, $330-370 \mathrm{~km}$ at midnight) than in winter $(200-260 \mathrm{~km}$ at noon, 270 $320 \mathrm{~km}$ at night). Again like $N \mathrm{mF} 2, h \mathrm{mF} 2$ has systematic differences with longitude. For example, noon $h \mathrm{mF} 2$ is 30-50 km higher in the "near-pole" sectors (especially the Australasian sector) than in "far-from-pole" sectors; but at midnight the reverse is true, $h \mathrm{mF} 2$ being about $50 \mathrm{~km}$ higher in the "far-from-pole" East Asian and South Atlantic sectors than in the "near-pole" sectors, possibly due to different wind patterns. When expressed in terms of the pressure-levels $Z$, the height $Z \mathrm{mF} 2$ of the noon F2 peak is fairly uniform at midlatitudes, mostly about 11.5 , but about 12 in the sectors where $h \mathrm{mF} 2$ is high. At midnight, $Z \mathrm{mF} 2$ varies from about 13.5 to 14.5 at midlatitudes, but reaches the top level $Z=15$ in parts of the "far-from-pole" sectors. Rishbeth et al. (2000b) compare the modelled behaviour of $h \mathrm{mF} 2$ with ionosonde data.

Raising solar activity from $F_{10.7}=100$ to $F_{10.7}=180$ causes $h \mathrm{mF} 2$ to rise, essentially because of thermal expansion. At noon, the increase in $h \mathrm{mF} 2$ is $100 \mathrm{~km}$ almost everywhere in middle and low latitudes, but only $50 \mathrm{~km}$ at high midlatitudes in equinox and winter. Expressed in terms of pressure-levels, the height $\mathrm{ZmF} 2$ of the noon $\mathrm{F} 2$ peak changes very little in most places (no more than about 0.2 unit), as expected if the change in $h \mathrm{mF} 2$ is just due to thermal expansion. There are larger changes of $Z \mathrm{mF} 2$ ( 0.5 unit) at higher midlatitudes in summer and equinox, especially in "far-frompole" sectors where the meridional winds are strong. At midnight, the increase of $h \mathrm{mF} 2$ is $60 \mathrm{~km}$ at winter midlatitudes, but $150 \mathrm{~km}$ in some places in the summer hemisphere. As at noon, $Z \mathrm{mF} 2$ does not change much from $F_{10.7}=100$ to $F_{10.7}=180$.

\subsection{The equatorial region}

It is well known that the F2-layer in low magnetic latitudes is strongly influenced by electric fields, the "fountain effect" described by Hanson and Moffett (1966) and many others. Both NmF2 and $h \mathrm{mF} 2$ have peculiarities in the equatorial zone. In the CTIP maps, the equatorial trough is well visible at March noon (Fig. 5), but at solstice it is almost concealed by the strong north-south asymmetry of $N \mathrm{mF} 2$. Vestiges of the trough can be seen at midnight in some longitudes.

At the magnetic equator, the "fountain effect" elevates noon $h \mathrm{mF} 2$ by $100-150 \mathrm{~km}$ (depending on longitude) above its level at midlatitudes (Fig. 8). At midnight the pattern is quite different: the daytime equatorial ridge is replaced by a sharp boundary at or near the magnetic equator, between higher $h \mathrm{mF} 2$ in the "magnetic summer hemisphere" and lower $h \mathrm{mF} 2$ in the 
"magnetic winter hemisphere". At March equinox, the pattern is more like the December than the June pattern.

Electric field effects are discussed more fully in Sect. 5 of Paper II, but it may be remarked here that (as expected from theory) the daytime equatorial trough is almost absent in the "no electric field" results mentioned in Sects. 2.1 and 2.4, there being only a narrow weak trough at the magnetic equator. Outside the equatorial zone, removal of the electric field produces little difference in either $N \mathrm{mF} 2$ or $h \mathrm{mF} 2$. A noticeable feature is that, despite the lack of longitude dependence in the Richmond et al. (1980) electric field model, the maps of $N \mathrm{mF} 2$ and $h \mathrm{mF} 2$ show marked longitude differences in the equatorial zone (Figs. 5 and 8). These must be due to some longitude-dependent factor, presumably connected in some way with the global thermospheric circulation (Paper II, Sect. 3).

\subsection{Annual and semiannual characteristics}

To investigate further the annual and semiannual variations of $N \mathrm{mF} 2$ and $h \mathrm{mF} 2$, Fourier components have been computed by taking the twelve monthly values and fitting mean, annual and semiannual components according to the equations

$$
N \mathrm{mF} 2=N_{0}+N_{1} \cos \left((\pi / 6)\left(t-\phi_{1}\right)\right)+N_{2} \cos \left((\pi / 3)\left(t-\phi_{2}\right)\right)
$$

$h \mathrm{mF} 2=h_{0}+h_{1} \cos \left((\pi / 6)\left(t-\phi_{1}\right)\right)+h_{2} \cos \left((\pi / 3)\left(t-\phi_{2}\right)\right)$

Table 2. Amplitudes and phases of Fourier components. Most features are magnetically aligned. In general, magnetic latitudes below $30^{\circ}$ or above $60^{\circ}$ are excluded. The phase (i.e. season at

\begin{tabular}{|c|c|c|c|}
\hline Parameter and unit & Mean & Annual & Semiannual \\
\hline
\end{tabular}

The amplitudes $N_{0}, N_{1}, N_{2}$ are in units of $10^{10} \mathrm{~m}^{-3}, h_{0}$, $h_{1}, h_{2}$ are in $\mathrm{km}$, and time $t$ is in months. The phases $\phi_{1}$ and $\phi_{2}$ denote the month of maximum, zero phase meaning the maximum is on 21 December. The phases should be accurate to $1 / 2$ month. Note that the 12monthly components (amplitudes $A_{1}, h_{1}$ ) may be either "annual" or "seasonal", depending on whether they have the same or opposite phase $\left(\phi_{1}\right)$ in North and South Hemispheres. Table 2 gives a simplified summary of the results at midlatitudes.

Tests were made to compare the annual/semiannual amplitude ratios $\left(N_{1} / N_{2}\right)$ obtained with $N \mathrm{mF} 2$ averaged over the period 11-14 LT with those for noon (12 LT) only; there was no significant difference. This was done because of the marked seasonal variation in the shape of the local time variation of $\mathrm{NmF} 2$. At midlatitudes in winter, $N \mathrm{mF} 2$ peaks sharply near noon (12 LT), but in summer the variation is much flatter, often with a depression around noon.

The phases of $N \mathrm{mF} 2$ are very consistent. The annual component peaks at winter solstice almost everywhere, the summer/winter boundary being at the magnetic equator. The semiannual component peaks at equinox everywhere, except in the magnetic equatorial zone where it is so small that the computed phase is unreliable. It seems that in the simulations, the semiannual variation is suppressed by the imposed electric field because, in the "no electric field" runs, a strong semiannual effect exists in the equatorial zone as it does in the real ionosphere. Further investigation is needed, using a more realistic model of the low-latitude electric fields. When plotted as maps, the mean, annual and semiannual amplitudes all show alignment with

which the annual and semiannual components are at maximum) is shown in italics. The terms "magnetic summer/winter" mean that
the boundary is at the magnetic, not the geographic equator

the boundary is at the magnetic, not the geographic equator (65) near-pole, $55 \%$ far-f far-from-pole longitudes) $10-20 \%$ at low midlatitude.

Patchy: $30-40 \%$ in $\mathrm{N}$ midlatitudes, $40-50 \%$ idlatitudes; Summer in low midlatitudes, 0-20 at midlatitudes, but 25 in $\mathrm{S}$ around longitude $0^{\circ}$.

tchy at midlatitudes: $30-50$ near-pole longitude, small at Magnetic summer
Patchy: peaks around $55^{\circ} \mathrm{N}$ 
magnetic latitude. This is evident too in maps of the amplitude ratios $\left(N_{1} / N_{0}\right),\left(N_{2} / N_{0}\right)$ and $\left(N_{1} / N_{2}\right)$, Fig. 9 . The top-left panel of Fig. 9 shows the large annual amplitudes of the "winter anomaly", peaking around the "near-pole" longitudes $60^{\circ} \mathrm{W}-0^{\circ}$ in the north and $120^{\circ} \mathrm{E}-180^{\circ} \mathrm{E}$ in the south. The semiannual component is quite uniform at midlatitudes. At midnight (Fig. 9, right) the prominent features are mostly associated with either the equatorial zone or the auroral zone, and are not discussed here. The complex structure in the midnight annual/semiannual map (bottom right) arises from the smallness of the semiannual component, and is not thought to be significant.

In looking at the maps of the annual/semiannual ratio (Fig. 9, bottom), note that if the ratio $\left(N_{1} / N_{2}\right)>2$ then midwinter $N \mathrm{mF} 2$ exceeds equinox $N \mathrm{mF} 2$ (given that the annual component is maximum at solstice and the semiannual component at equinox). Again, these results conform to the general pattern of the Torr and Torr maps (Fig. 2). The ratios $\left(N_{1} / N_{2}\right)$ are closely related to the months of maximum $N \mathrm{mF} 2$ discussed in Sect. 3.4.
CTIP Model

Noon
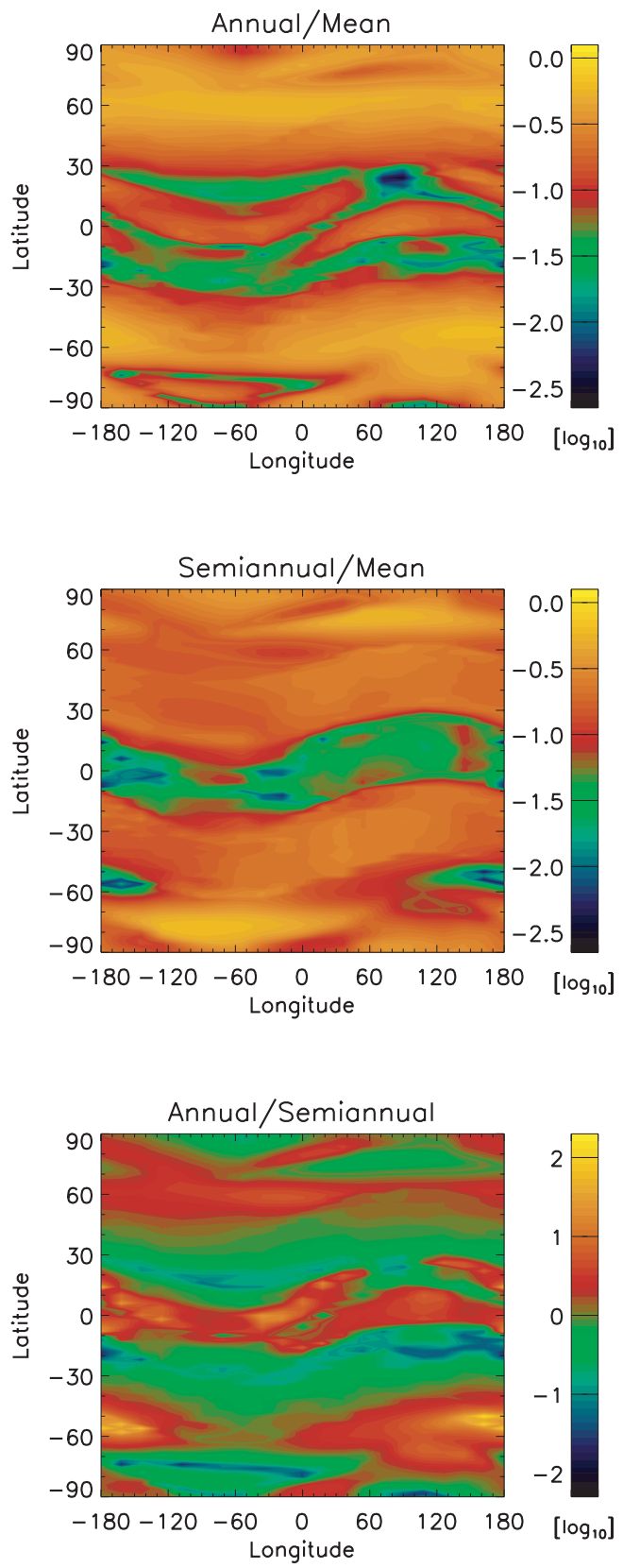

$\mathrm{NmF2}$
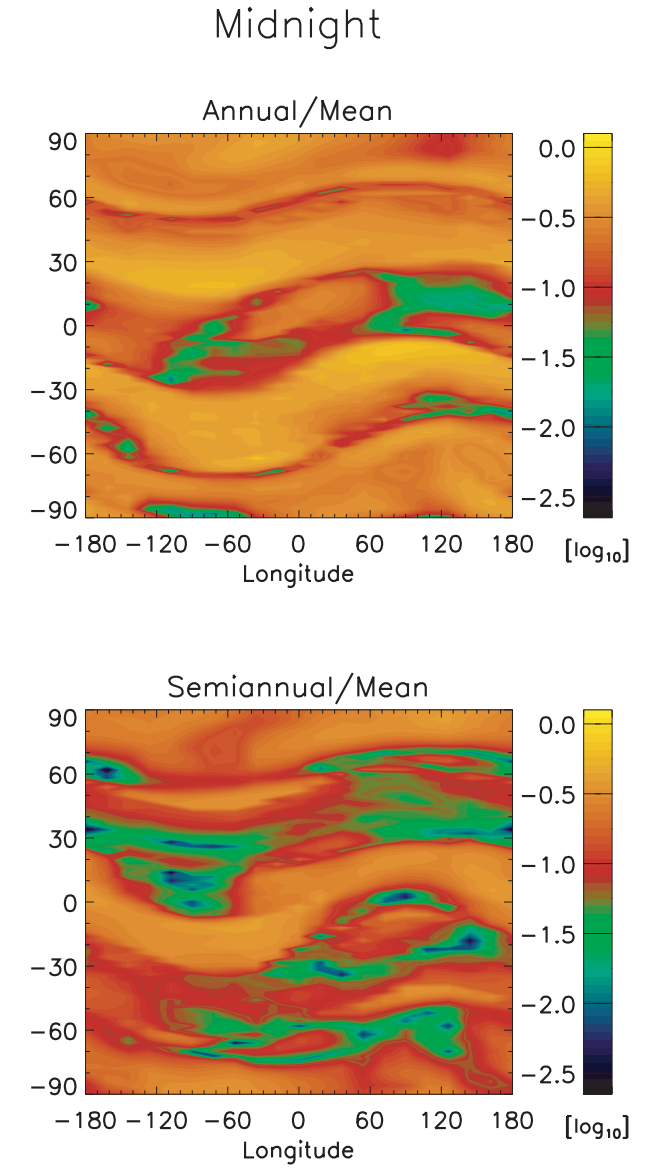

$F 10.7=100$ no tides

Midnight

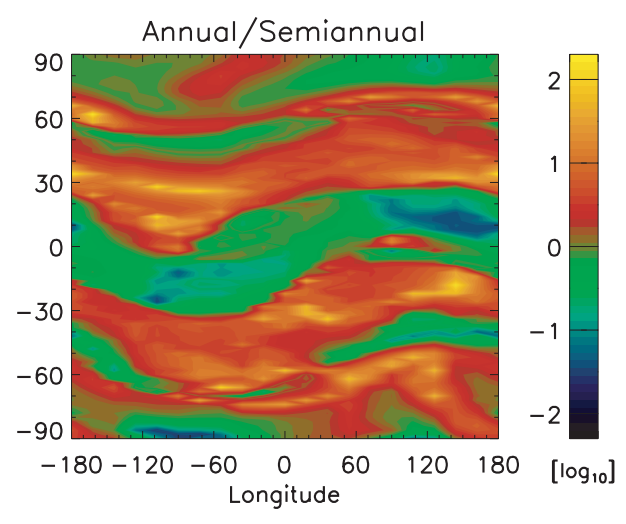

Fig. 9. Top to bottom: map of $\log$ (annual/mean), log (semiannual/mean), and log (annual/ semiannual) amplitude ratios, $F_{10.7}=100$. Left, noon; right, midnight 
Comparison of the top and middle panels of Fig. 10, for $F_{10.7}=100$ and $F_{10.7}=180$, shows few striking differences in the ratios $\left(N_{1} / N_{0}\right)$ and $\left(N_{1} / N_{2}\right)$, and by implication in $\left(N_{2} / N_{0}\right)$ also, though the annual amplitude does become larger at $F_{10.7}=180$ in the Australasian noon sector, as observed. Thus CTIP does not fully represent the enhanced winter anomaly at high solar activity. However, the calculations do not include the effect of vibrationally excited molecular nitrogen, which is important in summer at higher solar activity (Sect. 4.2).

\subsection{The annual, seasonal and semiannual components in $\mathrm{NmF} 2$ from ionosonde data}

Turning now to the observational data, and taking first the semiannual variations at 45 ionosonde stations, Yonezawa (1972) found the semiannual phase to be very consistent, with maxima in mid-April and mid-October for noon $N \mathrm{mF} 2$. Midnight $N \mathrm{mF} 2$ has the same phase at high solar activity, but the maxima move to mid-May and mid-November at low solar activity (Yonezawa's 1972, Fig. 3). Going from $20^{\circ}$ to $60^{\circ}$ geomagnetic
CTIP Model

Annual/Mean

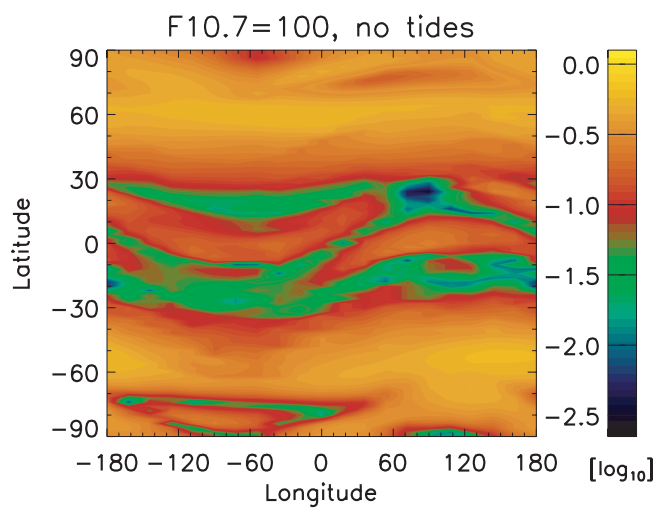

$\mathrm{F} 10.7=180$, no tides
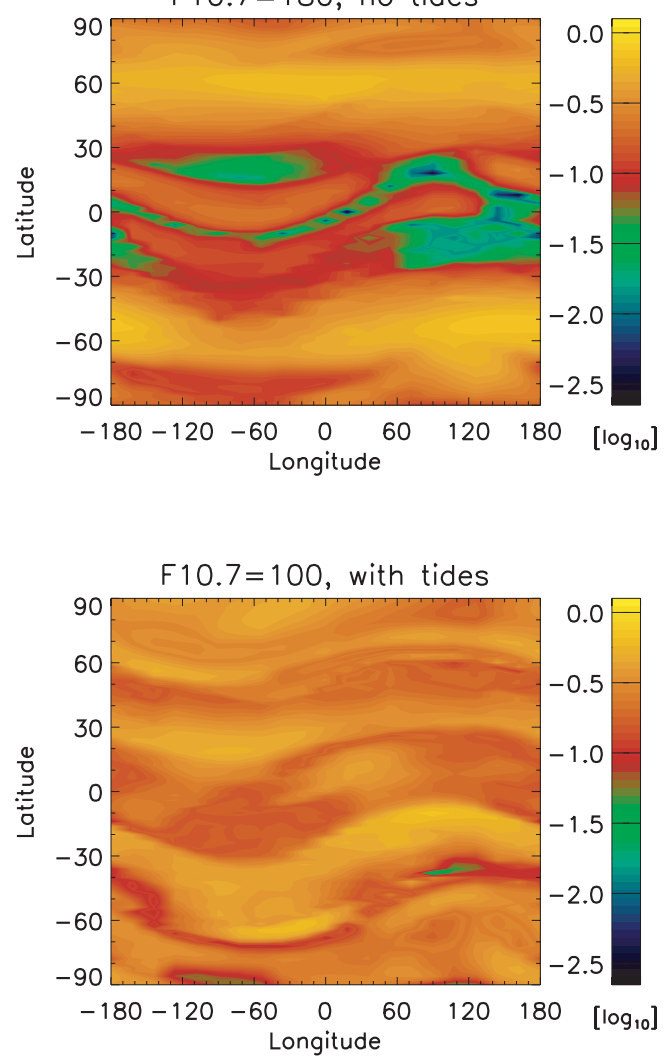

Annual/Semiannual

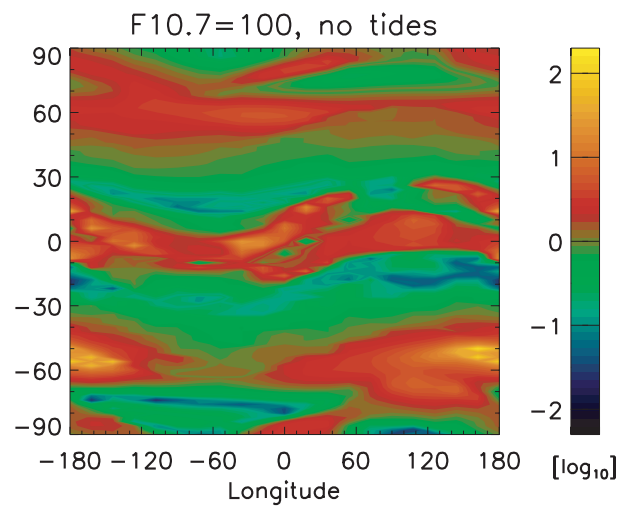

$F 10.7=180$, no tides

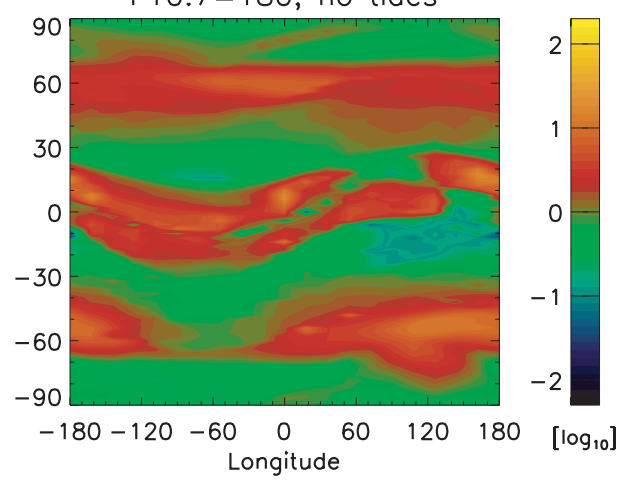

$F 10.7=100$, with tides

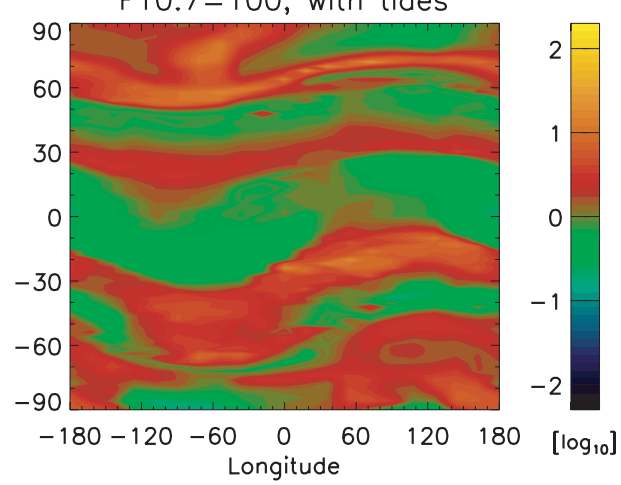

Fig. 10. (Left) map of $\log ($ annual $/$ mean) amplitude ratio at noon, $F_{10.7}=100$ and 180 , no tides; and $F_{10.7}=100$, with semidiurnal tides. (Right) map of $\log$ (annual/semiannual) amplitude ratio in noon $N \mathrm{mF} 2$, $F_{10.7}=100$ and 180 , no tides; and $F_{10.7}=100$, with semidiurnal tides 
latitude, the maxima become later by about one month (his Fig. 8). Both at noon and midnight, the semiannual amplitude is $15 \%-18 \%$ of the annual mean for sunspot numbers $R$ in the range 50 to 150 , which covers the CTIP runs (Yonezawa's Fig. 9). The midnight data show large semiannual amplitudes $(30 \%-40 \%$ of annual mean) in low magnetic latitudes, $15 \%-25 \%$ at high midlatitudes and about $15 \%$ in between (his Fig. 11); at noon the amplitude decreases weakly with latitude. Agreement with the CTIP results in Table 2 may be considered satisfactory.

Annual and seasonal variations cannot be separated in the data from a single station; it is necessary to combine data from opposite hemispheres. Yonezawa (1971) used nine north-south pairs of stations and fitted the data to a rather complicated formula that includes a semiannual modulation. Comparison with CTIP is not easy, largely because Yonezawa's (1971) analysis does not consider the longitude variations that are a feature of the CTIP results. Suffice it to say that at $R=50$ the seasonal amplitudes are $15-25 \%$ of the mean, and increase with $R$ particularly for pairs of stations in near-pole longitudes. Regarding the phase, midnight $N \mathrm{mF} 2$ peaks in summer, but for noon no simple summary is possible; the pattern found by Burkard (1951) and King and Smith (1968) gives a better description (Fig. 7). At midnight, maximum occurs at summer solstice. Again, these features are reasonably consistent with the CTIP results. The annual (nonseasonal) variation described by Yonezawa (1971) is easier to summarize. Its maximum is in January. Expressed as a percentage of the annual mean of $N \mathrm{mF} 2$, the annual variation is $26 \%$ at sunspot number $R=50$, decreasing to $18 \%$ at $R=150$, both for noon and midnight. In general it decreases with increasing geomagnetic latitude, with complications associated with the geomagnetic equatorial anomaly.

In contrast, CTIP does not give any overall annual variation, so in this respect fails to reproduce the observed ionosphere. Further investigation of the theory of Buonsanto (1986) is desirable. The CTIP results do contain longitude variations which, given that the ionosonde data analysis involves some selection by longitude, require further analysis to determine whether they have any bearing on the annual variation.

\subsection{Comparisons with ionosonde data for selected stations}

As explained in Sect. 1.1, Figs. 1 and 2 show ionosonde and CTIP data for $N \mathrm{mF} 2$ for midlatitude stations, three in each hemisphere, chosen to cover a range of geographic and geomagnetic locations. The present study is mainly concerned with the shape of the variation throughout the year, and the results are probably as good as can be expected without any adjustments or "tuning" of the inputs. For noon, CTIP reproduces well the strong semiannual variations at the "far-from-pole" stations, Port Stanley and Wakkanai, and the maxima either side of midwinter in longitudes nearer the magnetic poles, especially at the higher latitude stations Slough and Kerguelen. The longitude variations mentioned in Sect. 3.1 are not found in the ionosonde data. Comparing the monthly variations of two east-west pairs of stations, Wakkanai/Wallops Is and Kerguelen/Port Stanley, reveals some differences in winter that are consistent with their "near-pole" and farfrom-pole" locations.

As for midnight (Fig. 2), the match in shape between the model and the data is generally satisfactory. CTIP overestimates the semiannual variation, particularly at Slough, Hobart and Kerguelen, and does not fully reproduce the winter minimum at southern stations. Correcting for the variations of Sun-Earth distance makes little difference either to noon or midnight results; the expected $6 \%$ variation of $N \mathrm{mF} 2$ due to this cause corresponds to only 0.025 on the logarithmic scales in Figs. 1 and 2. The "calibration" of $N \mathrm{mF} 2$, i.e. the comparison of absolute values between the model and the data, is not of prime importance in the present study. Nevertheless, the match at noon is reasonably good, generally within $0.1-0.3$ on the scale of $\log N \mathrm{mF} 2$, corresponding to factors of 1.25-2. At midnight, when the computed electron density is sensitive to changes in loss coefficient or meridional winds, the model values are typically greater than ionosonde values by $0.2-0.6$ on the logarithmic scale, corresponding to factors of $1.5-4$.

\section{Other factors affecting the F2-layer}

\subsection{Effect of tides}

CTIP includes the principal diurnal tides generated within the thermosphere. In addition, there are semidiurnal tides, modes $(2,2),(2,3),(2,4)$ and $(2,5)$, imposed at the CTIP lower boundary (Sect. 2.5). They introduce a complex height-dependent wind pattern and modify slightly the thermospheric temperature. Our results, provisional as they are, indicate that the seasonal changes of wind velocity and composition at pressurelevel $Z=12$ (the midlatitude F2-peak), due to the semidiurnal tides, do not greatly modify the relative amplitudes of the mean, annual and semiannual components of noon $N \mathrm{mF} 2$. In the lower panels of Fig. 10, the most noticeable changes from the upper panels (no imposed semidiurnal tides) are in the equatorial zone. Tidal effects are examined in detail elsewhere (MüllerWodarg et al., 2000).

As these semidiurnal tidal oscillations are largely dissipated at E-region altitudes and deposit their energy there, some tidal effects may be expected in the lowlatitude electric fields, though these electric fields have little effect at mid-latitudes (Sect. 3.6). This implies that any tidal effects in the F2-layer at mid/high latitudes are caused primarily by changes in neutral winds and composition, which CTIP computes self-consistently, at least for the principal modes. 


\subsection{Excited states}

As suggested by Torr et al. (1980), F2-layer seasonal and solar cycle variations can also be influenced by changes in photochemical conditions, in particular the vibrational excitation of $\mathrm{N}_{2}$ and $\mathrm{O}_{2}$ which modifies the F2-layer loss coefficient. The effect of this vibrational excitation at middle and low latitudes was studied theoretically by Richards et al. (1994b), Ennis et al. (1995) and Jenkins et al. (1997). Their results show a major reduction of summer noon $N \mathrm{mF} 2$ by a factor of about 3 at very high solar activity, $F_{10.7}=200$. At the level $F_{10.7}=100$ used in the present work, in which the noon thermosphere temperature does not exceed $1000 \mathrm{~K}$, the factor is much smaller, about 1.5. This reduction of summer $\mathrm{NmF} 2$ would slightly increase the annual/mean ratios of noon $N \mathrm{mF} 2$ shown in Figs. 9 and 10. Pavlov (1998) showed that vibrational excitation of $\mathrm{O}_{2}$ may also be important.

For $F_{10.7}=180$, however, the noon temperature in middle and low latitudes reaches $1600 \mathrm{~K}$, and vibrational excitation has appreciable effect. If included in the modelling, the resulting depression of summer $N \mathrm{mF} 2$ would extend the areas of "winter maximum" and modify the semiannual amplitude in a complex way. So vibrationally excited $\mathrm{N}_{2}$ is one likely reason why the winter anomaly is more prominent at solar maximum than at solar minimum (the other reason being changes in the circulation, Sect. 3.2).

\section{Conclusions}

This work was undertaken to see how far the quiet-day annual and semiannual variations of $N \mathrm{mF} 2$ and $h \mathrm{mF} 2$ can be explained in terms of solar-driven photochemical and dynamical processes within the thermosphere itself, plus quiet-day auroral inputs and fields along the lines suggested by Millward et al. (1996a), but without invoking external processes such as tides and waves transmitted from the mesosphere or input from the solar wind. We now summarize the success of the CTIP simulations in explaining observed ionospheric and other phenomena. The major points have been discussed previously in Sects. 3 and 4. The latitude zones are defined in Sect. 2.2.

\subsection{Observed variations of midlatitude $\mathrm{N} m F 2$ and $\mathrm{h} m F 2$ successfully explained}

a. Dominance of winter anomaly at high midlatitudes, particularly in "near-pole" longitudes (adjacent to the magnetic poles)

b. Dominance of semiannual variation at high midlatitudes, in "far-from-pole" longitudes (away from the magnetic poles)

c. Dominance of semiannual variation in low midlatitudes generally

d. Seasonal sunrise anomaly in the rate of change near sunrise, $\mathrm{d}(N \mathrm{mF} 2) / \mathrm{d} t$ e. Winter anomaly seen only in daytime, $N \mathrm{mF} 2$ at midnight being greater in summer than in winter

f. Height of peak, $h \mathrm{mF} 2$, higher in summer than in winter.

\subsection{Observed variations at midlatitudes not successfully explained}

g. Winter anomaly stronger at solar maximum than at solar minimum, which may be due to the effect of vibrationally excited $\mathrm{N}_{2}$ in reducing summer $N \mathrm{mF} 2$ at solar maximum, Sect. 4.2, or of changes in the circulation pattern, Sect. 3.2

h. The annual anomaly, i.e. greatest worldwide electron density in December, beyond the 6\% effect of varying in Sun-Earth distance (not included in the model)

j. Semiannual variation in $h \mathrm{mF} 2$ (discussed by Rishbeth et al., 2000b).

\subsection{Processes or phenomena not included in this study}

k. Study of differences between March and September equinoxes

1. Absolute calibration; no attempt was made to calibrate modelled $N \mathrm{mF} 2$ against real data, though the comparison between CTIP and ionosonde data is reasonably satisfactory

m. Effects of vibrationally excited $\mathrm{N}_{2}$ or metastable $\mathrm{O}^{+}$ ions (Torr et al., 1980)

n. Detailed study of the equatorial or high latitude F2-layer

p. Relation to annual/semiannual variations in middle atmosphere (though there seems no need to invoke wave energy input from the middle atmosphere to explain variations of $\mathrm{NmF} 2$ )

q. Changes with solar activity in high latitude precipitation and electric fields.

\subsection{Other phenomena that need further study}

r. East-west longitude differences

s. Rapid change (within 2 months) between northern and southern solstice conditions

t. Regions of large $\left[\mathrm{O} / \mathrm{N}_{2}\right]$ ratio at high sub-auroral latitudes

u. Departures from diffusive equilibrium in upwelling regions

v. Effects of waves and tides transmitted from the mesosphere.

Possible mesospheric influences (p, v) are of topical interest in their own right; (r) and (s) are discussed in Sects. 3 and 4.6 of Paper II, respectively; (t, u) have been described by Rishbeth and Müller-Wodarg (1999), and are discussed further in Paper II which concentrates more on the physics.

Acknowledgements. This work was supported by the UK Natural Environment Research Council under the Antarctic Special Topic 
programme AST-4, and used the CRAY-YMP system at the Rutherford Appleton Laboratory. CTIP is a joint collaborative project between the Atmosphere Physics Laboratory of University College, London, the School of Mathematics and Statistics of the University of Sheffield and the NOAA Space Environment Center, Boulder, Colorado. We thank the ionospheric observatories whose data are used in this paper, and thank Paul Field for help with the computing. We are grateful to the late Michael Buonsanto for useful comments.

The Editor in Chief thanks H. Kohl and the late M. Buonsanto for their help in evaluating this paper.

\section{References}

Alcaydé, D., P. Bauer, and J. Fontinari, Long-term variations of thermospheric temperature and composition, J. Geophys. Res., 79, 629-637, 1974.

Allen, C. W., Critical frequencies, sunspots, and the sun's ultraviolet radiation, Terr. Magn. Atmos. Elect., 53, 433-448, 1948.

Appleton, E. V., Temperature changes in the higher atmosphere, Nature, 136, 52-53, 1935.

Becker, W., The temperature of the $\mathrm{F}$ region deduced from electron number density profiles, J. Geophys. Res., 72, 2001-2006, 1967.

Buonsanto, M. J., Possible effects of the changing Earth-Sun distance on the upper atmosphere, S. Pacific J. Nat. Sci., 8, 5865, 1986.

Burkard, O., Die halbjährige Periode der F2-Schicht-Ionisation, Archiv Meteorol. Bioklim. Wien, 4, 391-402, 1951.

Cox, L. P., and J. V., Evans, Seasonal variation of the $\mathrm{O} / \mathrm{N}_{2}$ ratio in the F1 region, J. Geophys. Res., 75, 6271-6286, 1970.

Dickinson, R. E., E. C., Ridley, and R. G., Roble, Thermospheric general circulation model with coupled dynamics and composition, J. Atmos. Sci., 41, 205-219, 1984.

Duncan, R. A., F-region seasonal and magnetic storm behaviour, J. Atmos. Terr. Phys., 31, 59-70, 1969.

Ennis, A. E., G. J. Bailey, and R. J. Moffett, Vibrational nitrogen concentration in the ionosphere and its dependence on season and solar cycle, Ann. Geophysicae, 13, 1164-1171, 1995.

Evans, D. S., T. J. Fuller-Rowell, S. Maeda, and J. C. Foster, Specification of the heat input to the thermosphere from magnetospheric processes using TIROS/NOAA auroral particle observations, Adv. Astronaut. Sci., 65, 1649-1667, 1988.

Evans, J. V., and L. P., Cox, Seasonal variation of the F1-region ion composition, J. Geophys. Res., 75, 159-164, 1970.

Field, P. R., H. Rishbeth, R. J. Moffett, D. W. Idenden, T. J. Fuller-Rowell, G. H. Millward, and A. D. Aylward, Modelling composition changes in F-layer storms, J. Atmos. Solar-Terr. Phys., 60, 523-543, 1998.

Forbes, J. M., and F. Vial, Monthly simulations of the solar semidiurnal tide in the mesosphere and lower thermosphere, J. Atmos. Terr. Phys., 51, 649-661, 1989.

Foster, J. C., J. M. Holt, R. G., Musgrove, and D. S., Evans, Ionospheric convection associated with discrete levels of particle precipitation, Geophys. Res. Lett., 13, 656-659, 1986.

Fuller-Rowell, T. J., The "thermospheric spoon": a mechanism for the semi-annual density variation, J. Geophys. Res., 103, 39513956, 1998

Fuller-Rowell, T. J., and D. S. Evans, Height-integrated Pedersen and Hall conductivity patterns inferred from the TIROSNOAA satellite data, J. Geophys. Res., 92, 7606-7618, 1987.

Fuller-Rowell, T. J., and D., Rees, Derivation of a conservation equation for mean molecular weight for a two-constituent gas within a three-dimensional, time-dependent model of the thermosphere, Planet. Space Sci., 31, 1209-1222, 1983.

Fuller-Rowell, T. J., D. Rees, S. Quegan, R. J. Moffett, M. V. Codrescu, and G. H. Millward, A coupled thermosphere-ionosphere model (CTIM), in STEP Handbook of ionospheric models Ed. R. W. Schunk, Utah State University, Logan, Utah, 217238,1996
Hanson, W. B., and R. J. Moffett, Ionization transport effects in the equatorial F region, J. Geophys. Res., 71, 5559-5572, 1966.

Hinteregger, H. E., K. Fukui, and B. R. Gilson, Observational, reference and model data on solar EUV, from measurements on AE-E, Geophys. Res. Lett., 8, 1147-1150.

Holton, J. R., An introduction to dynamic meteorology, Academic Press, San Diego, CA, 1982.

Jenkins, B., G. J. Bailey, A. E. Ennis, and R. J. Moffett, The effect of vibrationally excited nitrogen on the low-latitude ionosphere, Ann. Geophysicae, 15, 1422-1428, 1997.

Ivanov-Kholodnii, G. S., Semiannual variations in aeronomy and geomagnetism, Geomagn. Aeron., (English Edition), 13, 823839, 1973

King, J. W., and P. A. Smith, The seasonal anomaly in the behaviour of the F2-layer critical frequency, J. Atmos. Terr. Phys., 30, 1707-1713, 1968.

Lal, Chaman, Global F2 layer ionization and geomagnetic activity, J. Geophys. Res., 97, 12 153-12 159, 1992.

Lal, Chaman, Solar wind and equinoctial maxima in geophysical phenomena, J. Atmos. Terr. Phys., 60, 1017-1024, 1998.

Mauersberger, K., D. C. Kayser, W. E. Potter, and A. O. Nier, Seasonal variation of neutral thermospheric constituents in the northern hemisphere, J. Geophys. Res., 81, 7-11, 1976.

Millward, G. H., H. Rishbeth, T. J. Fuller-Rowell, A. D. Aylward, S. Quegan, and R. J. Moffett, Ionospheric F2 layer seasonal and semiannual variations, J. Geophys. Res., 101, 5149-5156, 1996a.

Millward, G. H., R. J. Moffett, S. Quegan, and T. J. FullerRowell, A coupled thermosphere-ionosphere-plasmasphere model (CTIP), in STEP Handbook of ionospheric models, Ed. R. W. Schunk, Utah State University, Logan, Utah, 239-280, 1996b.

Müller-Wodarg, I. C. F., A. D. Aylward, and T. J. Fuller-Rowell, Tidal oscillations in the thermosphere: a theoretical investigation of their sources, J. Atmos. Terr. Phys., 62, in press, 2000.

Offermann, D., Composition variations in the lower thermosphere, J. Geophys. Res., 79, 4281-4293, 1974.

Paetzold, H. K., and H. Zschörner, An annual and a semiannual variation of the upper air density, Geofis. Pura Appl., 48, 85-92, 1961.

Pavlov, A. V., The role of vibrationally excited oxygen and nitrogen in the ionosphere during the undisturbed and geomagnetic storm period of 6-12 April 1990, Ann. Geophysicae, 16, 589601, 1998.

Prölss, G. W., and U. von Zahn, ESRO 4 gas analyser results. 2. Direct measurement of changes in the neutral composition during an ionospheric storm, J. Geophys. Res., 79, 2535-2539, 1974.

Richards, P. G., J. A. Fennelly, and D. G. Torr, EUVAC: a solar EUV flux model for aeronomic calculations, J. Geophys. Res., 99, 8981-8992, 1994a.

Richards, P. G., D. G. Torr, B. W. Reinisch, R. R. Gamache, and P. J. Wilkinson, F2 peak electron density at Millstone Hill and Hobart: comparison of measurement and theory at solar maximum, J. Geophys. Res., 99, 15 005-15 016, 1994b.

Richmond, A. D., M. Blanc, B. A. Emery, R. H. Wand, B. G. Fejer, R. F. Woodman, S. Ganguly, P. Amayenc, R. A. Behnke, C. Calderon, and J. V. Evans, An empirical model of quiet-day electric fields at middle and low latitudes, J. Geophys. Res., 85, 4658-4664, 1980.

Rishbeth, H., How the thermospheric circulation affects the ionospheric F2-layer, J. Atmos. Terr. Phys., 60, 1385-1402, 1998.

Rishbeth, H., and C. S. G. K. Setty, The F-layer at sunrise, J. Atmos. Terr. Phys., 21, 263-276, 1961.

Rishbeth, H., and I. C. F. Müller-Wodarg, Vertical circulation and thermospheric composition: a modelling study, Ann. Geophysicae, 17, 794-805, 1999.

Rishbeth, H., I. C. F. Müller-Wodarg, L. Zou, T. J. Fuller-Rowell, G. H. Millward, R. J. Moffett, D. W. Idenden, and A. D. 
Aylward, Annual and semiannual variations in the ionospheric F2-layer: II. Physical discussion, Ann. Geophysicae, companion paper, 2000a.

Rishbeth, H., K. J. F. Sedgemore-Schulthess, and T. Ulich, Semiannual and annual variations in the height of the ionospheric F2-peak, Ann. Geophysicae, 18, 285-299, 2000b.

Rothwell, P., Diffusion of ions between $F$ layers at magnetic conjugate points, in Proc. International Conference on the Ionosphere, Institute of Physics and Physical Society, London, 217-221, 1963.

Russell, C. T., and R. L. McPherron, Semiannual variation of geomagnetic activity, J. Geophys. Res., 78, 92-108, 1973.

Torr, M. R., and D. G. Torr, The seasonal behaviour of the F2layer of the ionosphere, J. Atmos. Terr. Phys., 35, 2237-2251, 1973.

Torr, D. G., M. R. Torr, and P. G. Richards, Causes of the F region winter anomaly, Geophys. Res. Lett., 7, 301-304, 1980.
Waldteufel, P., A study of seasonal changes in the lower thermosphere and their implications, Planet. Space Sci., 18, 741-748, 1972.

Walterscheid, R. L., The semiannual oscillation in the thermosphere as a conduction mode, J. Geophys. Res., 87, 10 527-10 $535,1982$.

Yonezawa, T., The solar-activity and latitudinal characteristics of the seasonal, non-seasonal and semi-annual variations in the peak electron densities of the F2-layer at noon and at midnight in middle and low latitudes, J. Atmos. Terr. Phys., 33, 889-907, 1971.

Yonezawa, T., Semi-annual variations in the peak electron densities of the F2- and E-layers, J. Radio Res. Labs., 19, 1-22, 1972.

Yonezawa, T., and Y. Arima, On the seasonal and non-seasonal annual variations and the semi-annual variation in the noon and midnight electron densities of the F2 layer in middle latitudes, J. Radio Res. Labs., 6, 293-309, 1959. 